\title{
How can nanotechnology help the fight against breast cancer?
}

Elisabetta Avitabile, ${ }^{1}$ Davide Bedognetti, ${ }^{2}$ Gianni Ciofani, ${ }^{3,4}$ Alberto Bianco, ${ }^{5 *}$ and Lucia Gemma Delogu, ${ }^{1,6,7^{*}}$

${ }^{1}$ Department of Chemistry and Pharmacy, University of Sassari, Via Vienna 2, 07100 Sassari, Italy

${ }^{2}$ Immunology and Therapy Section, Division of Translational Medicine, Sidra Medical and Research Center, Doha, Qatar

${ }^{3}$ Smart Bio-Interfaces, Istituto Italiano di Tecnologia, Viale Rinaldo Piaggio 34, 56025 Pontedera, Italy

${ }^{4}$ Department of Mechanical and Aerospace Engineering, Politecnico di Torino, Corso Duca degli Abruzzi 24, 10129 Torino, Italy

${ }^{5}$ University of Strasbourg, CNRS, Immunology, Immunopathology and Therapeutic Chemistry, UPR 3572, 67000 Strasbourg, France

${ }^{6}$ Istituto di Ricerca Pediatrica Città della Speranza, Corso Stati Uniti 4, 35129 Padova, Italy

${ }^{7}$ Dipartimento di Scienze Chimiche e Farmaceutiche, University of Trieste, via Licio Giorgeri 1, 34127 Trieste, Italy

*Corresponding author: Alberto Bianco, a.bianco@ibmc-cnrs.unistra.fr; Lucia Gemma Delogu luciagemmadelogu@yahoo.it

Keywords: breast cancer, nanomaterials, imaging, drug delivery, theranostics 


\begin{abstract}
In this Review we provide a broad overview on the use of nanotechnology for the fight against breast cancer (BC). Nowadays, detection, diagnosis, treatment, and prevention may be possible thanks to the application of nanotechnology to the clinical practice. Taking into consideration the different forms of $\mathrm{BC}$ and the disease status, nanomaterials can be designed to reach the most forefront objectives of modern therapy and diagnosis. We here analyzed in details three main groups of nanomaterial applications for BC treatment and diagnosis. We have identified several types of drugs successfully conjugated with nanomaterials. We have analyzed the main important imaging techniques and all nanomaterials used to help non-invasive, early detection of the lesions. Moreover, we have examined theranostic nanomaterials as unique tools, combining imaging, detection, and therapy for BC. This state of the art provides a useful guide depicting how nanotechnology can be used to overcome current barriers in BC clinical practice, and how it will shape the future scenario of treatments, prevention, and diagnosis, revolutionizing the current approaches, i.e., reducing suffering related to chemotherapy.
\end{abstract}

\title{
1. Introduction
}

Breast cancer represents a malignant tumor where breast cells grow out of control and overcrowd normal cells. $\mathrm{BC}$ represents the most common type of cancer affecting women worldwide, and it is the second leading cause of death in the United States with 253000 new cases estimated in $2017 .^{1}$ When BC occurs, it is crucial, for the prognosis, to get early detection, followed by opportune treatments including surgery and chemotherapy. Nowadays, the most important clinical analyses comprise mammogram, ultrasound exams, and nuclear magnetic resonance imaging (MRI). Moreover, biopsy and blood chemistry studies help for a more accurate diagnosis of BC. Around 4.9 million breast biopsies are performed every year in the world, and 3.2 million of them are checked for screen detection of non-palpable breast lesions, of which a third is found to be malignant. ${ }^{2}$ 
However, by considering the current methods of BC diagnosis, any doctor can ensure a survival rate close to $100 \%$. On the other hand, if we focus on BC therapy, many current treatments are invasive, involving several breast biopsies, wire-guided localization, and eventually surgical removal. All current treatments including chemotherapy and prophylactic strategies are disfiguring, invasive, and associated with significant side effects. ${ }^{3}$

For all these reasons new diagnosis strategies and new effective and less toxic therapies are urgently needed. The recent advances in technology and engineering have led to the application of nanotechnology in medicine with the development of new nanoscale biomedical systems. ${ }^{4}$ Nanomaterials have been explored for biomedical research because of their extraordinary physicochemical characteristics. In particular, cancer nanotechnology has proposed excellent approaches to cancer detection, diagnosis, and treatment with limited toxicity compared to the traditional cancer therapy. ${ }^{5}$ In this context, nanotechnology can create human-made materials in the nanoscale range, the same scale where cellular and biological processes take place. ${ }^{6}$ The major potential of cancer nanotechnology includes the possibility to engineer nanovehicles with multiple molecules that, because of their small size, can penetrate tumors with high specificity, consequently with significantly fewer side effects. ${ }^{7-9}$ Furthermore, techniques for nonsurgical ablation of tumors have been developed, leading to the complete destruction of tumor cells by the direct application of thermal and chemical therapies using nanomaterials, composed of metals, lipids, or polymers. ${ }^{10}$ Therefore, cancer nanotechnology brings in the scenario of $\mathrm{BC}$ oncology huge expectations, and nanomaterials can be adapted the different BC forms and disease status. Because of the high degree of control, the characteristics of human-made nanotools can ensure new perspectives. Nanomaterials in BC can act as: i) drug nanocarriers, ii) nanodiagnostic tools, and iii) theranostic tools.

Regarding drug delivery, nanomaterials can be designed to transport chemotherapeutic drugs directly to the breast cells using specific antibodies to target the cancer site. ${ }^{11}$ Doxorubicin (Dox) linked to nanomaterials is the most investigated drug for cancer therapy. Very recently the group of Ferrari has 
described an injectable nanoparticle generator (iNPG), consisting of a discoidal micrometer-sized particle that can be loaded with Dox conjugated to poly(L-glutamic acid) (pDox). ${ }^{12}$ Intravenously injected iNPG-pDox accumulates into the tumor region and shows enhanced efficacy in mouse models of metastatic BC.

In the context of the development of diagnostic tools, there are many successful examples of nanomaterials applied to visualize BC [i.e. superparamagnetic iron oxide nanoparticles (SPIONs) and magnetic nanoparticles (MNPs)]. Different studies have reported a sensitivity of $73-100 \%$ and a specificity of $92-98 \%$ in the lymph node using SPIONs. ${ }^{13}$ Among other advantages, SPIONs are useful for the early detection by MRI, displaying also a good immune-compatibility and echogenic properties. ${ }^{14}$ Today other nanotechnology-enabled systems are in clinical trials. For example, a $\left[{ }^{18} \mathrm{~F}\right]-$ FAC isodeoxycytidine analogue for deoxycytidine kinase (DCK) labeled with fluorine ${ }^{18} \mathrm{~F}$, was proposed as a novel PET imaging probe. ${ }^{15}$ Nanoparticle MRI contrast agents that bind the $\alpha \mathrm{v} \beta 3$ intregrin, expressed on the surface of the newly developing blood vessels associated with early tumor development, were developed. ${ }^{16}$ Lymphotrophic superparamagnetic nanoparticles developed by the MIT-Harvard Center for Cancer Nanotechnology Excellence were used to identify small, otherwise undetectable, lymph node metastases. ${ }^{16}$

Before initiation of a cancer treatment, it is essential to carry out diagnostic imaging procedures to understand the type of cancer lesion. In this context, theranostic agents can combine diagnostic and therapeutic strategies into one procedure. ${ }^{17}$ Hosoya H. et al. ${ }^{18}$ described a hydrogel-based nanoplatform conjugated with Dox that enables ligand-directed tumor targeting and multimodal imaging. The data obtained using this strategy suggest that targeted hydrogel photothermal therapy represents a functional theranostic application such as image-guided approaches for diagnostic and therapeutic monitoring. Another revolutionary nanomaterial, graphene, and in particular graphene oxide (GO), has been studied for medical applications including tissue engineering, drug delivery, 
and gene transfection; many studies have explained its potential as molecularly-targeted and dualmodality imaging agent for in vivo imaging of $\mathrm{BC}{ }^{19}$

In this Review, our purpose is to point out what are the most promising nanomaterials that can perform a breakthrough revolution in the scenario of $\mathrm{BC}$. We provide a thorough overview of nanomaterials that have been so far investigated for the fight against BC, analyzing the most interesting publications present in the literature. We analyze the applications on drug delivery, imaging, and theranostics. We discuss all specific potentialities of the nanotechnology tools to overcome current barriers, to reduce toxicity, and to avoid suffering from anticancer treatments. This review aims to shed light on the challenges and hope offered by the different nanomaterials in the fight against $\mathrm{BC}$. We propose a comprehensive analysis of the nanomaterials enrolled in this oncology context.

\section{Overview and studies selection criteria}

Initially, we have analyzed in details three main nanomaterial applications for BC: i) drug delivery, ii) imaging, and iii) theranostics.

For this analysis, we performed a PubMed search using the following keywords: breast cancer, nanotechnology, nanomedicine, nanoparticles, nanomaterials, drug delivery, theranostics, and imaging. Keyword searching was also performed in different combinations. High impact review articles served as additional tools. The list of reported studies includes all retrieved publications from 2009 to December 2017. In Table S1, S2 and S3 we show a full and deep characterization of all applications based ontype of materials, conjugated drugs, imaging modialities, applications other than imaging, model, type of species examined (human, mouse and their combination), other types of cancer other than BC.

Figure 1 represents the number of publications over the years, the types of applications on therapy and diagnosis and the types of species examined in the cited works. The trend, from 2009 to December 
2017, indicates an oscillating tendency in the studies on BC (Fig. 1A); i.e., the number of retrieved publications in 2011 was 1.5 higher compared to 2009. After a clear decrease in 2012, the state of publications in all the following years was higher than 2009. Imaging is the first application (58\%), while $35 \%$ of the articles are referred to theranostic applications combined with drug delivery (Fig. 1B). Besides, drug delivery, a single application, is reported in $7 \%$ of the works. In Fig. $1 \mathrm{C}$ we show the relative percentage of publications describing human cell lines (in vitro and ex vivo), mice (in vivo, vitro, and ex vivo), or both. Although there are no many differences regarding the percentage of publications of the examined species, we found that the majority of the studies has been carried out in humans cells (39\%), $28 \%$ in mice, and $33 \%$ in both of them. International variations in BC incidence rates reflect differences in the availability of early detection tools as well as risk factors. ${ }^{20}$ In this context, we analyzed the countries where BC studies were carried out, taking into consideration the affiliation of the corresponding author (Fig. S1). We found that the majority of the studies (39\%) were conducted in USA, 26\% in China, 5\% in South Korea, 4\% in Japan, Singapore and India, 3\% in UK, $2 \%$ in Canada, Italy, Iran and Australia; a very few studies were conducted in other countries $(<2 \%)$. By the analysis of these percentages, we could conclude that there is no correlation between countries and incidence of BC. In fact, considering countries like United States where there is a high number of scientists, it is obvious to expect a larger amount of published works. A careful analysis of these data showed that there is not a strong correlation between the number of studies published and the relative incidence of BC. More developed countries represent about one-half of all BC cases with $38 \%$ of mortality. In fact, as reported in the pie graph (Fig. S1), USA, China, South Korea has got the highest percentage of studies compared to the other countries, but it was estimated that the higher mortality from BC occurs in Asian countries, as Qatar, India, and Iran.

Since BC may lead to metastasis in other regions of human body, many scientists focused at the same time on other cancer forms together with BC. We found that many authors studied BC specific ligand/cell surface also identified in other type of cancers, or BC overexpressed receptors using other cancers as negative controls. Therefore, we report other types of cancer investigated with BC (Fig. 
2). Lung cancer were studied in $22 \%$ of the papers, pancreatic and prostatic cancer in $19 \%$ of the papers, ovarian in $13 \%$. Melanoma, colon and liver cancers were studied in $6 \%$ of the publications and the other types of cancer including gastric, glioblastoma and bone cancer resulted in $3 \%$ of the cases (Fig. 2).

\section{Drug Delivery}

Drug delivery is a key nanotechnology application. In Table S1 we illustrate all publications on drug delivery in the context of BC. However, this type of application alone is reported in only the $7 \%$ of the cases considered. Indeed, in many examples, drug delivery applications refer to theranostic applications (corresponding to $35 \%$ of the studies). Analyzing the different publications, we found several types of drugs used in drug delivery or in combination leading to theranostic nanomaterials (Fig. 3). These drugs comprise Dox, herceptin, paclitaxel (PTX), dextran, curcumin, mitoxantrone, tamoxifen, methotrexate, pentoxifylline, and docetaxel. Dox represents the most important anticancer chemotherapeutic drug. ${ }^{21}$ Indeed, its ability to intercalate DNA bases, inhibiting the topoisomerase II enzyme during DNA transcription was widely demonstrated. ${ }^{22}$ Many studies used nanomaterials conjugated with Dox as an innovative cancer therapy. ${ }^{22-27}$ Herceptin was used for the treatment of metastatic BC, thanks to its properties of blocking cells proliferation. ${ }^{28-33}$ Recently, Wang et al. ${ }^{34}$ reported a synthesis of a particular multifunctional anti-cancer complex based on functionalized magnetic nanoparticles (MNPs) and quantum dots (QDs) with a dual-drug combination. In detail, the PTX/MNPs/QDs@ Biotin-PEG-PCDA nanoparticles nanoparticles have shown a high uptake by BC cells (MCF-7/ADR) and good drug release. These nanoparticles are able to combine various proprieties useful for imaging (QDs), targeted delivery and uptake (MNPs), and dual drug treatment using two drugs (i.e., PTX and curcumin). Curcumin, a natural compound extracted from curcuma longa, helped to obtain a high PTX accumulation in the tumor target and induces a down-regulation of drug efflux transporters. Moreover, PTX has shown excellent efficacy in a wide spectrum of cancer 
treatments, but its formulation has led to serious side effects in patients, as neurotoxicity, nephrotoxicity and allergic reaction. Modified PTX as nanomicelles was developed to overcome these obstacles and multidrug resistance..$^{35}$

Zhao et al. ${ }^{36}$ described hybrid paclitaxel nanocrystals that integrated fluorescent molecules for therapeutic and imaging in a breast tumor. The authors observed a more efficient anticancer effect of this system in mice with breast tumor than in mice treated with pure PTX. The hybrid PTX nanocrystals have shown the ability to easily accumulate in the tumor area following intravenous administration. Others described PTX release directly into the tumor sites for theranostic nanomedicine application ${ }^{34-37}$ and drug delivery. ${ }^{38}$ In the third position of the most important drugs used in the cancer fight, we found curcumin, a compound endowed of interesting properties including an anti-inflammatory action. ${ }^{39}$ Curcumin can specifically modulate the expression of proteins in proliferating cells, in adhesion and in migration, and it is used as an anticancer drug to prevent metastatic formation or to limit cancer progression..$^{40,41}$

Furthermore, other types of drugs such as dextran $33,42,43$ or docetaxel ${ }^{44,45}$ were loaded into nanoparticles for cancer detection, while mitoxantrone, ${ }^{46}$ tamoxifen, ${ }^{47}$ methotrexate, ${ }^{48}$ pentoxifylline, ${ }^{49}$ docetaxel, ${ }^{50,51}$ cisplatin and gemcitabine were combined for the development of theranostics materials. ${ }^{52}$ Recently, the group of Chan provided quantification of the delivery efficiency of nanoparticles at the tumor site. They reported a bombshell work whose meta-analysis suggested that very few "targeted" nanoparticles reach the target. According to this analysis, only 7 out of 1000 engineered nanoparticles are able to accumulate into the tumor in vivo. ${ }^{53}$

\section{Imaging}

Nowadays, nanotechnology based on imaging represents a very promising solution for non-invasive investigations of cancer lesions. We found that in $58 \%$ of the examined studies the first approach against $\mathrm{BC}$ is based on the use of nanotools for imaging (Fig. 1B). Breast imaging can be undertaken 
using MRI, the most commonly available modality, thanks to its rapidity and high resolution (Fig. 4A) ${ }^{54}$ Different nanoparticles with appropriate surface modification have been used in vivo as MRI contrast agents because of their high magnetization and nano-size ${ }^{55}$ In particular, the surface coating was exploited to create non-toxic and biocompatible nanomaterials (see Table S2). ${ }^{56-78}$ For example, Medarova et $a l .{ }^{79}$ have modified SPIONs with Cy5.5 dye and conjugated them to specific peptides. This tumor-specific contrast agent was able to successfully target the under-glycosylated MUC-1 (uMUC-1) tumor antigen, present in over $90 \%$ cases of BCs.

MRI is followed by two other techniques, namely fluorescence imaging (FI) $)^{5,64,78,80-119}$ and confocal laser scanning microscopy (CLSM) (Fig. 4A). ${ }^{58,64,67,73-75,120-134}$ Both of them have shown to be excellent imaging tools for many in vitro studies on murine and human cancer cells.

Pan et al. ${ }^{120}$ described in vitro cancer detection of human cells (MCF-7) using fluorescent quantum dots (QDs) as luminescent probes for targeted imaging. The authors described a new strategy to prepare QDs formulated in folate-decorated nanoparticles (PLA-TPGS/TPGS-COOH) (PLA-TPGS, poly(lactide)-D- $\alpha$-tocopheryl polyethylene glycol succinate) for BC detection and diagnosis at its early stage. They demonstrated that functionalization with a copolymer was able to improve imaging sensitivity with reduced side effects on normal cells. Another imaging technique used in BC studies is the near-infrared (NIR) optical imaging, $56,79,83,96,97,99,107,112,127,132,135-143$ which represents the fourth most exploited type of modality in the total of the examined studies. Through NIR fluorescence images, the authors analyzed directly in vivo the biodistribution of many nanomaterials in different organs and their elimination. Bardhan et $a l .{ }^{56}$ used modified gold nanoshells (AuNSs) with fluorophores to enhance the fluorescence in live mice grafted with human cancer cell lines over $72 \mathrm{~h}$. The nanocomplex, conjugated with specific antibodies to target human epidermal growth factor receptor 2 (HER2) overexpressed in BC, provided significant information regarding the distribution of nanomaterial, and represents a new approach for cancer therapy and non-invasive treatment for soft-tissue tumors. ${ }^{56}$

Moreover, we found that computed tomography $(\mathrm{CT})^{70,113,139,144-152}$ is at the fifth position in terms 
of number of works related to $\mathrm{BC}$, while other techniques are less used, including superconducting quantum interference device (SQUID), ${ }^{94,} 153$ surface enhanced Raman scattering (SERS), ${ }^{81,154-159}$ synchrotron X-ray micro-imaging (X-ray), ${ }^{150,152,160,161}$ positron emission tomography (PET), ${ }^{106,115,}$ 142, 162 and fluorescence molecular tomography (FMT). ${ }^{70,73}$ We reported that single-photon emission computed tomography (SPECT), ${ }^{163}$ ultrasound imaging (US),${ }^{71}$ intermolecular quantum coherence (iMQC), ${ }^{164}$ optical coherence tomography (OCT), ${ }^{165}$ ultrashort echo time (UTE) ${ }^{166}$ are in the last positions as imaging techniques used (Fig. 4A). Focusing on the imaging tools, we found that the first most studied nanomaterials are SPIONs (Fig. 4B).

Many publications have shown the interesting potential of SPIONs for tumor detection, cancer therapy and drug delivery. ${ }^{13,54,57,59,61,64,67,68,74-79,94,100,104,145,148,164,166-170}$ SPIONs are applied as molecular imaging probes due to their monodisperse size distribution, but for biomedical applications, a surface modification [i.e., with poly(2-hydroxyethyl aspartamide)] is necessary to make them stable under physiological conditions and to avoid the uptake by phagocytic cells. ${ }^{57} \mathrm{~A}$ recent publication has shown their use for gene therapy. Lin et al. ${ }^{74}$ discovered that SPIONs conjugated with small interfering RNA (siRNA) were able to silence the target messenger RNA, consequently reducing the expression of P-glycoprotein (P-gp), a cell membrane protein responsible of multidrug resistance. Through this gene therapy, the authors demonstrated an excellent downregulation of P-gp in MCF-7/ADR human BC cell lines in orthotopic mouse model.

In the same way of SPIONs, other small size $(5-8 \mathrm{~nm})$ magnetic nanoparticles (MNPs) have also shown the same characteristics in terms of, $58,69,70,72,73,83,102,125,126,131,134,139,153,171$ biodistribution, and ability to carry more compounds thanks to their high surface availability. In this context, Yigit $e t$ $a l .{ }^{171}$ used MNPs linked to microRNA (miRNA) for gene therapy. The treatment of human BC cells (MDA-MB-231) in vitro and in vivo with the nanocomplex down-regulated a pro-metastatic microRNA (miR-10b) arresting the metastatic process, thus preventing the formation of lymph node metastases. Regarding QDs, we found that they are in the third position as nanomaterials for imaging. Thanks to their fluorescence properties upon excitation, their high brightness and photostability, they 
represent unique nanomaterials ideal for in vivo imaging in animal cancer models, as shown in the measurement of the receptor expression level of type I insulin-like growth factor receptor (IGFIR) involved in BC proliferation and metastasis. ${ }^{122}$ QDs have been coated with polymer to enhance biocompatibility, ${ }^{64,89,92,95,101,114,120,133,172}$ or conjugated with antibodies to detect overexpressed receptors. ${ }^{85,88,90,91,98,99,107-110,116,122,135}$

The fourth position is held by gold nanoparticles, used for tumor detection, diagnosis, and cancer therapy, due to the possibility of an easy surface modification. ${ }^{173}$ The advantages of these nanomaterials include non-cytotoxicity, chemical stability, and high affinities for biomolecules. ${ }^{121}$ Indeed, they can scatter visible and near-infrared light through surface plasmon resonance, so that they have been used in many microscopic techniques including CLSM, ${ }^{121,130,174} \mathrm{CT},{ }^{113,147,149,150,152}$ FI, ${ }^{5,87,103,113}$ and other imaging techniques like X-ray, ${ }^{150,152,160}$ NIR imaging ${ }^{141}$ and SERS. ${ }^{155,175}$ Finally, other imaging nanomaterials (Fig. 4B) such as poly(lactic-co-glycolic) acid nanoparticles (PLGA) ${ }^{71,80,97,176}$ mesoporous silica nanoparticles (MSNs), ${ }^{75,86,140,142}$ liposomes, ${ }^{93,100,144,146,177,178}$ silica- AuNSs, ${ }^{56,137,154,165}$ gold nanorods (GNRs), ${ }^{78,84}$ carbon nanotubes (CNTs), ${ }^{82,}{ }^{129}$ nanoglobules ${ }^{62,66}$, graphene oxide, ${ }^{115,163}$ and nanodiamonds (NDs) ${ }^{179}$ have been studied for breast tissue imaging and cancer therapy (see Table S2).

\section{Theranostics}

Recently, nanotechnology has provided new strategies that combine therapy and diagnosis approaches. The introduction of the word "theranostics" represents a well-established field of nanotechnology where multifunctional materials can be used for the detection and treatment of cancer disease in a single procedure. Of particular importance is the simultaneous combination of contrast agents and therapeutic functions using chemically-modified nanoparticles or fluorescent probes. ${ }^{180 \text {, }}$ ${ }^{181}$ In Table S3 we report a characterisation of all theranostic applications found in the literature for BC. Regarding nanoparticles, we found MNPs in the first position in terms of theranostic materials investigated, followed by calcium phosphosilicate composite nanoparticles (CPSNPs), liposomes, 
AuNPs and GNRs, AuNSs, CNTs and polymers (Fig. 5). Theranostic MNPs have demonstrated excellent performances in tumor detection, ${ }^{182-185}$ drug delivery, ${ }^{184,} 185$ and cancer therapy in mice model studies. ${ }^{186,187}$ Part of the works examined were carried out in vitro on MDA-MB-231, ${ }^{40,41}$ MCF-7, $, 1,47,188,{ }^{189} \mathrm{H} 1299$ human cell lines, ${ }^{188}$ as preliminary studies to evaluate the response to cancer therapy. Basuki et al. ${ }^{188}$ described the theranostic application of MNPs loaded with polymers and Dox in in vitro experiments using MCF-7 on H1299 human cell lines. The authors demonstrated accumulation of MNP-Dox in lung and BC cell lines through MRI and Dox release to cancer cells using CLSM and FI techniques. For theranostic, GNPs, AuNSs have raised interest in photodynamic therapy, ${ }^{190,191}$ photothermal therapy, ${ }^{180,192-194}$ ultrasonography ${ }^{192}$ and gene therapy. ${ }^{180}$ On the other hand, in the context of imaging, AuNPs have shown main applications regarding tumor detection. ${ }^{18}$, $29,195-200$

In the third position we found other known theranostic materials such as MSNs used for tumor targeting and drug delivery, ${ }^{30,}{ }^{201-203}$ GNRs for tumor detection and drug delivery, ${ }^{31,32,204}$ gene therapy, ${ }^{205}$ and photothermal therapy. ${ }^{206,207}$ We also found liposomes for tumor detection and drug delivery, 46, 50, 208, 209 and other new theranostics systems like CNTs ${ }^{48,210-213}$ and CPSNPs. ${ }^{214,} 215$ In particular, we have shown that CNTs have good echogenic properties like contrast agents, with a promising future in the field of theranostic applications. ${ }^{216}$ Even though positioned in the fourth position, QDs have acquired more importance in the field of theranostic applications. Rizvi et al. ${ }^{217}$ reported an in vitro experiment using QDs loaded with antibodies for HER-2 localization in fixed and live cells (SK-BR-3 and MCF-7 cells). This study underlines how QDs coated with mercaptoundecanoic acid appeared non-toxic up to $24 \mathrm{~h}$ of exposure, and an excellent in vitro imaging agent. For this reason, QDs can be potentially used for targeted therapy in image-guided surgery and cancer therapy to directly destroy tumor cells. In addition to traditional nanomaterials, the combination of polymeric materials has opened a new way for theranostic nanomaterials, known as nano-complexes (Fig. 5). Their properties have allowed a controlled release of drugs in addition to 
many medical applications, like photoacoustic tomography, ${ }^{218}$ photothermal therapy, ${ }^{219-221}$ photodynamic therapy, ${ }^{222}$ drug delivery ${ }^{37,49,223-229}$ and cancer therapy. ${ }^{230-234}$

During the last years, graphene-based materials have been investigated in biomedical applications thanks to its unique intrinsic chemical and physical properties. ${ }^{235}$ Excellent electrical conductivity, ideal photothermal response, large surface area, and versatile chemistry have stimulated the researchers to explore graphene based materials for applications in tissue engineering, drug delivery, molecular imaging and others. For example, Shi et al. ${ }^{236}$ reported reduced GO (rGO) as an excellent photothermal agent that enabled in vivo tumor ablation. rGO could be also used as theranostic materials to integrate imaging and therapeutic components to fight cancer. ${ }^{236}$ Recent researches of nanotechnology based on other carbon nanomaterials as NDs, CNTs, and fullerenes have provided good results about their possibility to become theranostic agents in the different field of nanomedicine such as drug delivery, regenerative medicine, bioimaging. Carbon nano-onions (CNOs) showed the same vectorization characteristics possessed by CNTs, as we described in a previous work. ${ }^{237}$ Recently Bartelmess et al. ${ }^{238}$ demonstrated a simple cell-penetration capability of CNOs in an in vitro MCF-7 human BC cell line. Boron dipyrromethene (BODIPY) functionalized CNOs exhibited high fluorescence intensity for high-resolution imaging and did not show significant toxicity effects. These results make modified CNOs as new theranostic materials able to combine imaging, targeting and therapeutic modalities.

\section{Conclusions and future views}

We here reported a thorough and detailed review on nanoscale innovations against BC proposed in the last nine years. We have evidenced an increasing interest in the study of nanotechnological applications to BC. Nanotechnology offers a possibility for early breast lesion detection and search for more efficient therapies to significantly impact the degree of mortality of BC patients. Despite numerous studies on the application of nanotechnology in medicine, the hypothetical benefits still need to be clarified. Most of the nanomaterials tested have not been able to provide high efficiency 
for clinical use. Considering the intrinsic physicochemical properties of nanomaterials and all works analyzed here, superparamagnetic iron oxide nanoparticles, quantum dots, graphene and liposomes represent the best choice as advanced drug carriers for BC therapy. On the other hand, gold silica nanoparticles, nanoshells, nanorods, nanocages, and nanotubes were especially studied as photothermal agents under radiofrequency or magnetic field activation in non-invasive imaging and cancer therapy. ${ }^{239}$ Regarding drug delivery, nanoparticles have been engineered as drug vehicles to bring drug directly at the tumor site, to reduce toxic side effects of antineoplastic agents, and to enhance combinatorial drug delivery. Among all reported studies we highlighted the most promising ones. Recent studies focused on new strategies based on a combination therapy through a coadministration of multiple drugs using a single treatment. For example, this approach was carried out by Murugan et al. ${ }^{240}$ to describe nanocarrier mediated inhibitory effects of topotecan and quercetin on BC cells like a new targeted therapeutic strategy to treat cancer. These revolutionary nanocarries have shown an excellent intracellular release of loaded drugs with important molecularl-induced modifications leading to structural charges in endoplasmatic reticulum, nucleus and mitochondria in tumor cells. ${ }^{240}$

Nanotechnology can offer potential nanomaterials for creating new methods for detection, targeting and killing $\mathrm{BC}$ at different stages. Several authors reported the problematic use of many nanomaterials because of their non-specific toxic effects in in vivo animal models. One of the major advantages of using nanoparticles are based on the possibility to modify their characteristics to face physical and biological barriers after injection. However, the analysis of the recent publications disclosed that the delivery efficiency has not advanced during the last ten years.

Regarding innovative approaches able to accelerate the nanotool integration into the clinic, we would like to mention single cell techniques and in particular single cell mass cytometry. We recently described how this approach could reveal the effect of graphene and nanomaterials in general on immune cells. ${ }^{241}$ Being aware that single cell mass cytometry can be useful in the context of BC, as 
proven recently by the group of Bodenmiller, ${ }^{242}$, we believe it will be of interest to apply this approach on nanotools to validate their effect on $\mathrm{BC}$ treatment.

In conclusion, despite the numerous studies found in the literature, only a few nanomaterials or nanocompounds will move on from the pre-clinical phase and will be selected for clinical trials. Indeed, the research on biocompatibility are still at the early stage. Given the great interest reported in recent years, graphene could be one of the promising nanomaterial to fight $\mathrm{BC}$. Moreover, at present, the possibility to control the nanoparticles transport and the real delivery efficiency in the body for cancer treatment remains the real challenge for nanotechnology-based tools against BC.

\section{Conflicts of interest}

There are no conflicts to declare.

\section{Acknowledgements}

This work was partly supported by the Centre National de la Recherche Scientique (CNRS), by the Agence Nationale de la Recherche (ANR) through the LabEx project Chemistry of Complex Systems (ANR-10-LABX-0026_CSC) (to A.B.), and by the International Center for Frontier Research in Chemistry (icFRC). The authors gratefully acknowledge financial support from ANR (ANR-15GRFL-0001-05), from MIUR JTC Graphene 2015 (G-IMMUNOMICS project), the European Union HORIZON 2020 research and innovation programme under MSCA RISE 2016 project Carbo-Immap grant. n. 734381 and Italian MIUR (PRIN call 2015, project: 2015TWP83Z).

\section{References}

1. R. L. Siegel, K. D. Miller and A. Jemal, CA Cancer J. Clin., 2017, 67, 7-30.

2. L. A. Torre, F. Bray, R. L. Siegel, J. Ferlay, J. Lortet-Tieulent and A. Jemal, CA Cancer J. Clin., 2015, 65, 87-108.

3. D. B. Cordera and A. Marx, E cancer medical science 2014, 8, 495.

4. M. Ahmed and M. Douek, Bio.Med. Res. Int., 2013, 2013, 281230.

5. B. D. Chithrani, J. Stewart, C. Allen and D. A. Jaffray, Nanomedicine, 2009, 5, 118-127.

6. M. Ferrari, Nat. Rev. Cancer, 2005, 5, 161-171.

7. D. Peer, J. M. Karp, S. Hong, O. C. Farokhzad, R. Margalit and R. Langer, Nat. Nanotechnol., 2007, 2, 751-760. 
8. S. Sharma, V. R. Kotamraju, T. Molder, A. Tobi, T. Teesalu and E. Ruoslahti, Nano Lett., 2017, 17, 1356-1364.

9. S. R. Alves Rico, A. Z. Abbasi, G. Ribeiro, T. Ahmed, X. Y. Wu and D. de Oliveira Silva, Nanoscale, 2017, 9, 10701-10714.

10. K. F. Chu and D. E. Dupuy, Nat. Rev. Cancer, 2014, 14, 199-208.

11. A. Allegra, G. Penna, A. Alonci, V. Rizzo, S. Russo and C. Musolino, Anticancer Agents Med. Chem., 2011, 11, 669-686.

12. R. Xu, G. Zhang, J. Mai, X. Deng, V. Segura-Ibarra, S. Wu, J. Shen, H. Liu, Z. Hu, L. Chen, Y. Huang, E. Koay, Y. Huang, J. Liu, J. E. Ensor, E. Blanco, X. Liu, M. Ferrari and H. Shen, Nat. Biotechnol., 2016, 34, 414-418.

13. G. Nakai, M. Matsuki, T. Harada, N. Tanigawa, T. Yamada, J. Barentsz and Y. Narumi, J. Magn. Reson. Imaging, 2011, 34, 557-562.

14. R. Weissleder and M. Nahrendorf, Proc. Natl. Acad. Sci. USA, 2015, 112, 14424-14428.

15. C. J. Shu, D. O. Campbell, J. T. Lee, A. Q. Tran, J. C. Wengrod, O. N. Witte, M. E. Phelps, N. Satyamurthy, J. Czernin and C. G. Radu, J. Nucl. Med., 2010, 51, 1092-1098.

16. N. C. Institute, (https://nano.cancer.gov/learn/now/clinical-trials.asp).

17. S. S. Kelkar and T. M. Reineke, Bioconj. Chem., 2011, 22, 1879-1903.

18. H. Hosoya, A. S. Dobroff, W. H. Driessen, V. Cristini, L. M. Brinker, F. I. Staquicini, M. Cardo-Vila, S. D'Angelo, F. Ferrara, B. Proneth, Y. S. Lin, D. R. Dunphy, P. Dogra, M. P. Melancon, R. J. Stafford, K. Miyazono, J. G. Gelovani, K. Kataoka, C. J. Brinker, R. L. Sidman, W. Arap and R. Pasqualini, Proc. Natl. Acad. Sci. USA, 2016, 113, 1877-1882.

19. M. Orecchioni, R. Cabizza, A. Bianco and L. G. Delogu, Theranostics, 2015, 5, 710-723.

20. J. Ferlay, I. Soerjomataram, R. Dikshit, S. Eser, C. Mathers, M. Rebelo, D. M. Parkin, D. Forman and F. Bray, Int. J. Cancer, 2015, 136, E359-386.

21. Q. Zhang, Q. Jiang, N. Li, L. Dai, Q. Liu, L. Song, J. Wang, Y. Li, J. Tian, B. Ding and Y. $\mathrm{Du}$, ACS Nano, 2014, 8, 6633-6643.

22. A. K. Jain, N. K. Swarnakar, M. Das, C. Godugu, R. P. Singh, P. R. Rao and S. Jain, Mol. Pharm., 2011, 8, 1140-1151.

23. S. P. Sherlock, S. M. Tabakman, L. Xie and H. Dai, ACS Nano, 2011, 5, 1505-1512.

24. J. Gautier, E. Munnier, A. Paillard, K. Herve, L. Douziech-Eyrolles, M. Souce, P. Dubois and I. Chourpa, Int. J. Pharm., 2012, 423, 16-25.

25. Z. Wang, Y. Yu, W. Dai, J. Cui, H. Wu, L. Yuan, H. Zhang, X. Wang, J. Wang, X. Zhang and Q. Zhang, Biomaterials, 2013, 34, 756-764.

26. Y. Huang, K. Mao, B. Zhang and Y. Zhao, Mater. Sci. Eng. C, 2017, 70, 763-771.

27. Y. Xia, X. Wu, J. Zhao, J. Zhao, Z. Li, W. Ren, Y. Tian, A. Li, Z. Shen and A. Wu, Nanoscale, 2016, 8, 18682-18692.

28. M. Jang, Y. I. Yoon, Y. S. Kwon, T. J. Yoon, H. J. Lee, S. I. Hwang, B. L. Yun and S. M. Kim, Korean J. Radiol., 2014, 15, 411-422.

29. J. B. Otis, H. Zong, A. Kotylar, A. Yin, S. Bhattacharjee, H. Wang, J. R. Baker, Jr. and S. H. Wang, Oncotarget, 2016, 7, 36002-36013.

30. A. Milgroom, M. Intrator, K. Madhavan, L. Mazzaro, R. Shandas, B. Liu and D. Park, Coll. Surf. B Biointer., 2014, 116, 652-657.

31. M. Eghtedari, A. V. Liopo, J. A. Copland, A. A. Oraevsky and M. Motamedi, Nano Lett., 2009, 9, 287-291.

32. C. Wang, J. Chen, T. Talavage and J. Irudayaraj, Angew. Chem. INt. Ed., 2009, 48, 27592763.

33. T. J. Chen, T. H. Cheng, C. Y. Chen, S. C. Hsu, T. L. Cheng, G. C. Liu and Y. M. Wang, J. Biol. Inorg. Chem., 2009, 14, 253-260.

34. J. Wang, F. Wang, F. Li, W. Zhang, Y. Shen, D. Zhou and S. Guo, J. Mater. Chem. B, 2016, 4, 2954-2962. 
35. H. J. Yao, R. J. Ju, X. X. Wang, Y. Zhang, R. J. Li, Y. Yu, L. Zhang and W. L. Lu, Biomaterials, 2011, 32, 3285-3302.

36. R. Zhao, C. P. Hollis, H. Zhang, L. Sun, R. A. Gemeinhart and T. Li, Mol. Pharm., 2011, 8, 1985-1991.

37. S. Ferber, H. Baabur-Cohen, R. Blau, Y. Epshtein, E. Kisin-Finfer, O. Redy, D. Shabat and R. Satchi-Fainaro, Cancer Lett., 2014, 352, 81-89.

38. M. Frasconi, Z. Liu, J. Lei, Y. Wu, E. Strekalova, D. Malin, M. W. Ambrogio, X. Chen, Y. Y. Botros, V. L. Cryns, J. P. Sauvage and J. F. Stoddart, J. Am. Chem. Soc., 2013, 135, 11603-11613.

39. A. L. Palange, D. Di Mascolo, C. Carallo, A. Gnasso and P. Decuzzi, Nanomedicine, 2014, 10, 991-1002.

40. M. M. Yallapu, S. F. Othman, E. T. Curtis, N. A. Bauer, N. Chauhan, D. Kumar, M. Jaggi and S. C. Chauhan, Int. J. Nanomed., 2012, 7, 1761-1779.

41. M. M. Yallapu, S. F. Othman, E. T. Curtis, B. K. Gupta, M. Jaggi and S. C. Chauhan, Biomaterials, 2011, 32, 1890-1905.

42. G. Ling, P. Zhang, W. Zhang, J. Sun, X. Meng, Y. Qin, Y. Deng and Z. He, J. Contr. Release, 2010, 148, 241-248.

43. M. Kumar, M. Yigit, G. Dai, A. Moore and Z. Medarova, Cancer Res, 2010, 70, 7553-7561.

44. J. H. Kang and Y. T. Ko, Int. J. Nanomed., 2015, 10 Spec Iss, 33-45.

45. X. Tang, Y. Liang, X. Feng, R. Zhang, X. Jin and L. Sun, Mater. Sci. Eng. C, 2015, 49, 348355.

46. Y. He, L. Zhang, D. Zhu and C. Song, Int. J. Nanomed., 2014, 9, 4055-4066.

47. M. Heidari Majd, D. Asgari, J. Barar, H. Valizadeh, V. Kafil, A. Abadpour, E. Moumivand, J. S. Mojarrad, M. R. Rashidi, G. Coukos and Y. Omidi, Coll. Surf. B Biointer., 2013, 106, 117-125.

48. M. Das, S. R. Datir, R. P. Singh and S. Jain, Mol. Pharm., 2013, 10, 2543-2557.

49. J. Peng, T. Qi, J. Liao, B. Chu, Q. Yang, Y. Qu, W. Li, H. Li, F. Luo and Z. Qian, Theranostics, 2014, 4, 678-692.

50. M. S. Muthu, S. A. Kulkarni, A. Raju and S. S. Feng, Biomaterials, 2012, 33, 3494-3501.

51. P. Dadras, F. Atyabi, S. Irani, L. Ma'mani, A. Foroumadi, Z. H. Mirzaie, M. Ebrahimi and R. Dinarvand, Eur. J. Pharm. Sci., 2017, 97, 47-54.

52. Z. Yaari, D. da Silva, A. Zinger, E. Goldman, A. Kajal, R. Tshuva, E. Barak, N. Dahan, D. Hershkovitz, M. Goldfeder, J. S. Roitman and A. Schroeder, Nat. Commun., 2016, 7, 13325.

53. S. Wilhelm, A. J. Tavares, Q. Dai, S. Ohta, J. Audet, H. F. Dvorak and W. C. W. Chan, Nat. Rev. Mater., 2016, 1, 16014.

54. L. Johnson, G. Charles-Edwards and M. Douek, Cancers, 2010, 2, 1884-1894.

55. J. A. Kaplan, M. W. Grinstaff and B. N. Bloch, Eur. J. Radiol., 2016, 26, 866-873.

56. R. Bardhan, W. Chen, M. Bartels, C. Perez-Torres, M. F. Botero, R. W. McAninch, A. Contreras, R. Schiff, R. G. Pautler, N. J. Halas and A. Joshi, Nano Lett., 2010, 10, 49204928.

57. H. M. Yang, C. W. Park, M. A. Woo, M. I. Kim, Y. M. Jo, H. G. Park and J. D. Kim, Biomacromolecules, 2010, 11, 2866-2872.

58. S. Mazzucchelli, M. Colombo, C. De Palma, A. Salvade, P. Verderio, M. D. Coghi, E. Clementi, P. Tortora, F. Corsi and D. Prosperi, ACS Nano, 2010, 4, 5693-5702.

59. C. Prashant, M. Dipak, C. T. Yang, K. H. Chuang, D. Jun and S. S. Feng, Biomaterials, 2010, 31, 5588-5597.

60. Y. Onuki, I. Jacobs, D. Artemov and Y. Kato, Biomaterials, 2010, 31, 7132-7138.

61. R. Meier, T. D. Henning, S. Boddington, S. Tavri, S. Arora, G. Piontek, M. Rudelius, C. Corot and H. E. Daldrup-Link, Radiology, 2010, 255, 527-535.

62. M. Tan, X. Wu, E. K. Jeong, Q. Chen and Z. R. Lu, Biomacromolecules, 2010, 11, 754-761. 
63. P. Chandrasekharan, D. Maity, C. X. Yong, K. H. Chuang, J. Ding and S. S. Feng, Biomaterials, 2011, 32, 5663-5672.

64. Y. F. Tan, P. Chandrasekharan, D. Maity, C. X. Yong, K. H. Chuang, Y. Zhao, S. Wang, J. Ding and S. S. Feng, Biomaterials, 2011, 32, 2969-2978.

65. E. K. Lim, H. O. Kim, E. Jang, J. Park, K. Lee, J. S. Suh, Y. M. Huh and S. Haam, Biomaterials, 2011, 32, 7941-7950.

66. M. Tan, Z. Ye, E. K. Jeong, X. Wu, D. L. Parker and Z. R. Lu, Bioconj. Chem., 2011, 22, 931-937.

67. F. M. Kievit, Z. R. Stephen, O. Veiseh, H. Arami, T. Wang, V. P. Lai, J. O. Park, R. G. Ellenbogen, M. L. Disis and M. Zhang, ACS Nano, 2012, 6, 2591-2601.

68. X. H. Shan, H. Hu, F. Xiong, N. Gu, X. D. Geng, W. Zhu, J. Lin and Y. F. Wang, Eur. J. Radiol., 2012, 81, 95-99.

69. L. Cheng, K. Yang, Y. Li, X. Zeng, M. Shao, S. T. Lee and Z. Liu, Biomaterials, 2012, 33, 2215-2222.

70. P. M. Peiris, R. Toy, E. Doolittle, J. Pansky, A. Abramowski, M. Tam, P. Vicente, E. Tran, E. Hayden, A. Camann, A. Mayer, B. O. Erokwu, Z. Berman, D. Wilson, H. Baskaran, C. A. Flask, R. A. Keri and E. Karathanasis, ACS Nano, 2012, 6, 8783-8795.

71. Y. Sun, Y. Zheng, H. Ran, Y. Zhou, H. Shen, Y. Chen, H. Chen, T. M. Krupka, A. Li, P. Li, Z. Wang and Z. Wang, Biomaterials, 2012, 33, 5854-5864.

72. H. Chen, L. Wang, Q. Yu, W. Qian, D. Tiwari, H. Yi, A. Y. Wang, J. Huang, L. Yang and H. Mao, Int. J. Nanomed., 2013, 8, 3781-3794.

73. Y. Zhang, B. Zhang, F. Liu, J. Luo and J. Bai, Int. J. Nanomed., 2014, 9, 33-41.

74. G. Lin, W. Zhu, L. Yang, J. Wu, B. Lin, Y. Xu, Z. Cheng, C. Xia, Q. Gong, B. Song and H. Ai, Biomaterials, 2014, 35, 9495-9507.

75. H. Yang, Y. Li, T. Li, M. Xu, Y. Chen, C. Wu, X. Dang and Y. Liu, Sci Rep, 2014, 4, 7072.

76. Y. Kato, W. Zhu, M. V. Backer, C. C. Neoh, S. Hapuarachchige, S. K. Sarkar, J. M. Backer and D. Artemov, J. Pharm. Res., 2015, 32, 3746-3755.

77. X. H. Shan, P. Wang, F. Xiong, N. Gu, H. Hu, W. Qian, H. Y. Lu and Y. Fan, Mol. Imaging Biol., 2016, 18, 24-33.

78. M. Khafaji, M. Vossoughi, M. R. Hormozi-Nezhad, R. Dinarvand, F. Borrnert and A. Irajizad, Sci. Rep., 2016, 6, 27847.

79. Z. Medarova, L. Rashkovetsky, P. Pantazopoulos and A. Moore, Cancer Res., 2009, 69, 1182-1189.

80. T. Betancourt, K. Shah and L. Brannon-Peppas, J. Mater. Sci. Mater. Med., 2009, 20, 387395.

81. S. Lee, H. Chon, M. Lee, J. Choo, S. Y. Shin, Y. H. Lee, I. J. Rhyu, S. W. Son and C. H. Oh, Biosens. Bioelectron., 2009, 24, 2260-2263.

82. E. I. Galanzha, E. V. Shashkov, T. Kelly, J. W. Kim, L. Yang and V. P. Zharov, Nat. Nanotechol., 2009, 4, 855-860.

83. L. Yang, X. H. Peng, Y. A. Wang, X. Wang, Z. Cao, C. Ni, P. Karna, X. Zhang, W. C. Wood, X. Gao, S. Nie and H. Mao, Clin. Cancer Res., 2009, 15, 4722-4732.

84. N. Chanda, R. Shukla, K. V. Katti and R. Kannan, Nano Lett., 2009, 9, 1798-1805.

85. E. L. Snyder, D. Bailey, M. Shipitsin, K. Polyak and M. Loda, Lab Invest., 2009, 89, 857866.

86. X. Hun and Z. Zhang, Spectrochim. Acta. Part A, Mol. Biomol. Spectr., 2009, 74, 410-414.

87. M. J. Crow, G. Grant, J. M. Provenzale and A. Wax, AJR Am. J. Roentgenol., 2009, 192, 1021-1028.

88. T. Jin, D. K. Tiwari, S. Tanaka, Y. Inouye, K. Yoshizawa and T. M. Watanabe, Mol. BioSyst., 2010, 6, 2325-2331.

89. C. Wu, T. Schneider, M. Zeigler, J. Yu, P. G. Schiro, D. R. Burnham, J. D. McNeill and D. T. Chiu, J. Am. Chem. Soc., 2010, 132, 15410-15417. 
90. K. Gonda, T. M. Watanabe, N. Ohuchi and H. Higuchi, J. Biol. Chem., 2010, 285, 27502757.

91. X. L. Liu, C. W. Peng, C. Chen, X. Q. Yang, M. B. Hu, H. S. Xia, S. P. Liu, D. W. Pang and Y. Li, Biochem. Biophys. Res. Commun., 2011, 409, 577-582.

92. Y. Wu, M. Chu, B. Shi and Z. Li, Mol. Biotechnol., 2011, 163, 813-825.

93. A. P. Mann, R. C. Bhavane, A. Somasunderam, B. Liz Montalvo-Ortiz, K. B. Ghaghada, D. Volk, R. Nieves-Alicea, K. S. Suh, M. Ferrari, A. Annapragada, D. G. Gorenstein and T. Tanaka, Oncotarget, 2011, 2, 298-304.

94. H. J. Hathaway, K. S. Butler, N. L. Adolphi, D. M. Lovato, R. Belfon, D. Fegan, T. C. Monson, J. E. Trujillo, T. E. Tessier, H. C. Bryant, D. L. Huber, R. S. Larson and E. R. Flynn, Breast Cancer Res., 2011, 13, R108.

95. A. J. Shuhendler, P. Prasad, H. K. Chan, C. R. Gordijo, B. Soroushian, M. Kolios, K. Yu, P. J. O'Brien, A. M. Rauth and X. Y. Wu, ACS Nano, 2011, 5, 1958-1966.

96. M. Q. Zhu, G. F. Zhang, C. Li, M. P. Aldred, E. Chang, R. A. Drezek and A. D. Li, J. Am. Chem. Soc., 2011, 133, 365-372.

97. C. Zheng, M. Zheng, P. Gong, D. Jia, P. Zhang, B. Shi, Z. Sheng, Y. Ma and L. Cai, Biomaterials, 2012, 33, 5603-5609.

98. W. Xu, L. Liu, N. J. Brown, S. Christian and D. Hornby, Molecules, 2012, 17, 796-808.

99. Q. Ma, Y. Nakane, Y. Mori, M. Hasegawa, Y. Yoshioka, T. M. Watanabe, K. Gonda, N. Ohuchi and T. Jin, Biomaterials, 2012, 33, 8486-8494.

100. C. Yan, Y. Wu, J. Feng, W. Chen, X. Liu, P. Hao, R. Yang, J. Zhang, B. Lin, Y. Xu and R. Liu, Int. J. Nanomed., 2013, 8, 245-255.

101. X. Hua, Z. Zhou, L. Yuan and S. Liu, Anal. Chim. Acta, 2013, 788, 135-140.

102. M. Heidari Majd, J. Barar, D. Asgari, H. Valizadeh, M. R. Rashidi, V. Kafil, J. Shahbazi and Y. Omidi, Adv. Pharm. Bull., 2013, 3, 189-195.

103. C. Ayala-Orozco, C. Urban, S. Bishnoi, A. Urban, H. Charron, T. Mitchell, M. Shea, S. Nanda, R. Schiff, N. Halas and A. Joshi, J. Contr. Release, 2014, 191, 90-97.

104. P. Guo, J. Huang, L. Wang, D. Jia, J. Yang, D. A. Dillon, D. Zurakowski, H. Mao, M. A. Moses and D. T. Auguste, Proc. Natl. Acad. Sci. USA, 2014, 111, 14710-14715.

105. T. K. Hill, A. Abdulahad, S. S. Kelkar, F. C. Marini, T. E. Long, J. M. Provenzale and A. M. Mohs, Bioconj. Chem., 2015, 26, 294-303.

106. H. Hong, F. Wang, Y. Zhang, S. A. Graves, S. B. Eddine, Y. Yang, C. P. Theuer, R. J. Nickles, X. Wang and W. Cai, ACS Appl. Mater. Interfaces, 2015, 7, 3373-3381.

107. A. Sasaki, Y. Tsukasaki, A. Komatsuzaki, T. Sakata, H. Yasuda and T. Jin, Nanoscale, 2015, 7, 5115-5119.

108. Q. M. Xiang, L. W. Wang, J. P. Yuan, J. M. Chen, F. Yang and Y. Li, Exp. Mol. Pathol., 2015, 99, 133-138.

109. J. P. Yuan, L. W. Wang, A. P. Qu, J. M. Chen, Q. M. Xiang, C. Chen, S. R. Sun, D. W. Pang, J. Liu and Y. Li, PloS One, 2015, 10, e0122734.

110. K. Gonda, M. Miyashita, H. Higuchi, H. Tada, T. M. Watanabe, M. Watanabe, T. Ishida and N. Ohuchi, Sci. Rep., 2015, 5, 14322.

111. P. Kumar and R. Srivastava, Mater. Sci. Eng. C, 2015, 57, 321-327.

112. T. Özel, S. White, E. Nguyen, A. Moy, N. Brenes, B. Choi and T. Betancourt, Lasers Surg. Med., 2015, 47, 579.

113. P. M. Peiris, P. Deb, E. Doolittle, G. Doron, A. Goldberg, P. Govender, S. Shah, S. Rao, S. Carbone, T. Cotey, M. Sylvestre, S. Singh, W. P. Schiemann, Z. Lee and E. Karathanasis, J. Pharm. Sci., 2015, 104, 2600-2610.

114. M. Michalska, A. Florczak, H. Dams-Kozlowska, J. Gapinski, S. Jurga and R. Schneider, Acta Biomater., 2016, 35, 293-304.

115. D. Yang, L. Feng, C. A. Dougherty, K. E. Luker, D. Chen, M. A. Cauble, M. M. Banaszak Holl, G. D. Luker, B. D. Ross, Z. Liu and H. Hong, Biomaterials, 2016, 104, 361-371. 
116. H. Chen, Y. Wang, T. Wang, D. Shi, Z. Sun, C. Xia and B. Wang, J. Nanobiotechnol., 2016, 14,52 .

117. B. K. Gupta, S. Singh, P. Kumar, Y. Lee, G. Kedawat, T. N. Narayanan, S. A. Vithayathil, L. Ge, X. Zhan, S. Gupta, A. A. Marti, R. Vajtai, P. M. Ajayan and B. A. Kaipparettu, Sci. Rep., 2016, 6, 32401.

118. K. C. Mei, J. Bai, S. Lorrio, J. T. Wang and K. T. Al-Jamal, Biomaterials, 2016, 106, 276285.

119. W. Hong, S. Lee, H. J. Chang, E. S. Lee and Y. Cho, Biomaterials, 2016, 106, 78-86.

120. J. Pan and S. S. Feng, Biomaterials, 2009, 30, 1176-1183.

121. J. L. Li, L. Wang, X. Y. Liu, Z. P. Zhang, H. C. Guo, W. M. Liu and S. H. Tang, Cancer Lett., 2009, 274, 319-326.

122. H. Zhang, X. Zeng, Q. Li, M. Gaillard-Kelly, C. R. Wagner and D. Yee, Brit. J. Cancer, 2009, 101, 71-79.

123. E. S. Day, L. R. Bickford, J. H. Slater, N. S. Riggall, R. A. Drezek and J. L. West, Int. J. Nanomed., 2010, 5, 445-454.

124. J. Pietkiewicz, K. Zielinska, J. Saczko, J. Kulbacka, M. Majkowski and K. A. Wilk, Eur. J. Pharm. Sci., 2010, 39, 322-335.

125. D. Granot and E. M. Shapiro, Magn. Reson. Med., 2011, 65, 1253-1259.

126. O. Veiseh, F. M. Kievit, H. Mok, J. Ayesh, C. Clark, C. Fang, M. Leung, H. Arami, J. O. Park and M. Zhang, Biomaterials, 2011, 32, 5717-5725.

127. C. Wang, H. Tao, L. Cheng and Z. Liu, Biomaterials, 2011, 32, 6145-6154.

128. S. Inoue, H. Ding, J. Portilla-Arias, J. Hu, B. Konda, M. Fujita, A. Espinoza, S. Suhane, M. Riley, M. Gates, R. Patil, M. L. Penichet, A. V. Ljubimov, K. L. Black, E. Holler and J. Y. Ljubimova, Cancer Res., 2011, 71, 1454-1464.

129. J. J. Khandare, A. Jalota-Badhwar, S. D. Satavalekar, S. G. Bhansali, N. D. Aher, F. Kharas and S. S. Banerjee, Nanoscale, 2012, 4, 837-844.

130. A. Kumar, H. Ma, X. Zhang, K. Huang, S. Jin, J. Liu, T. Wei, W. Cao, G. Zou and X. J. Liang, Biomaterials, 2012, 33, 1180-1189.

131. J. A. Tate, M. D. Savellano and P. J. Hoopes, Proc. SPIE Int. Soc. Opt. Eng., 2013, 8584, $85840 \mathrm{I}$.

132. U. Bazylinska, S. Drozdek, M. Nyk, J. Kulbacka, M. Samoc and K. A. Wilk, Langmuir, 2014, 30, 14931-14943.

133. E. Yaghini, H. D. Turner, A. M. Le Marois, K. Suhling, I. Naasani and A. J. MacRobert, Biomaterials, 2016, 104, 182-191.

134. S. Hapuarachchige, Y. Kato, E. J. Ngen, B. Smith, M. Delannoy and D. Artemov, PloS One, 2016, 11, e0156294.

135. A. Papagiannaros, J. Upponi, W. Hartner, D. Mongayt, T. Levchenko and V. Torchilin, BMC Med. Imaging, 2010, 10, 22.

136. W. J. Akers, Z. Zhang, M. Berezin, Y. Ye, A. Agee, K. Guo, R. W. Fuhrhop, S. A. Wickline, G. M. Lanza and S. Achilefu, Nanomedicine, 2010, 5, 715-726.

137. L. R. Bickford, G. Agollah, R. Drezek and T. K. Yu, Breast Cancer Res., 2010, 120, 547555.

138. L. G. Gutwein, M. C. Rule, A. K. Singh, M. A. Hahn, S. C. Brown, B. Moudgil and S. R. Grobmyer, Luminescence, 2011, 26, 390-396.

139. C. G. Hadjipanayis, H. Jiang, D. W. Roberts and L. Yang, Sem. Oncol., 2011, 38, 109-118.

140. L. G. Gutwein, A. K. Singh, M. A. Hahn, M. C. Rule, J. A. Knapik, B. M. Moudgil, S. C. Brown and S. R. Grobmyer, Int. J. Nanomed., 2012, 7, 351-357.

141. H. Yuan, C. G. Khoury, H. Hwang, C. M. Wilson, G. A. Grant and T. Vo-Dinh, Nanotechnol., 2012, 23, 075102.

142. F. Chen, T. R. Nayak, S. Goel, H. F. Valdovinos, H. Hong, C. P. Theuer, T. E. Barnhart and W. Cai, Mol. Pharm., 2014, 11, 4007-4014. 
143. H. Yamaguchi, M. Tsuchimochi, K. Hayama, T. Kawase and N. Tsubokawa, Int. J. Mol. Sci., 2016, 17, E1086.

144. E. Samei, R. S. Saunders, C. T. Badea, K. B. Ghaghada, L. W. Hedlund, Y. Qi, H. Yuan, R. C. Bentley and S. Mukundan, Jr., Int. J. Nanomed., 2009, 4, 277-282.

145. S. M. MacDonald, M. G. Harisinghani, A. Katkar, B. Napolitano, J. Wolfgang and A. G. Taghian, Int. J. Radiat. Oncol. Biol. Phys., 2010, 77, 1098-1104.

146. K. B. Ghaghada, C. T. Badea, L. Karumbaiah, N. Fettig, R. V. Bellamkonda, G. A. Johnson and A. Annapragada, Acad. Radiol., 2011, 18, 20-30.

147. J. F. Hainfeld, M. J. O'Connor, F. A. Dilmanian, D. N. Slatkin, D. J. Adams and H. M. Smilowitz, Brit. J. Radiol., 2011, 84, 526-533.

148. K. Motomura, M. Ishitobi, Y. Komoike, H. Koyama, A. Noguchi, H. Sumino, Y. Kumatani, H. Inaji, T. Horinouchi and K. Nakanishi, Ann. Surg. Oncol., 2011, 18, 3422-3429.

149. K. Li, S. Wen, A. C. Larson, M. Shen, Z. Zhang, Q. Chen, X. Shi and G. Zhang, Int. J. Nanomed., 2013, 8, 2589-2600.

150. L. E. Cole, T. Vargo-Gogola and R. K. Roeder, Biomaterials, 2014, 35, 2312-2321.

151. G. Balasundaram, C. J. Ho, K. Li, W. Driessen, U. S. Dinish, C. L. Wong, V. Ntziachristos, B. Liu and M. Olivo, Int. J. Nanomed., 2015, 10, 387-397.

152. L. E. Cole, T. Vargo-Gogola and R. K. Roeder, ACS Nano, 2015, 9, 8923-8932.

153. N. L. Adolphi, K. S. Butler, D. M. Lovato, T. E. Tessier, J. E. Trujillo, H. J. Hathaway, D. L. Fegan, T. C. Monson, T. E. Stevens, D. L. Huber, J. Ramu, M. L. Milne, S. A. Altobelli, H. C. Bryant, R. S. Larson and E. R. Flynn, Contrast Media Mol. Imaging, 2012, 7, 308319.

154. Y. Huang, V. P. Swarup and S. W. Bishnoi, Nano Lett., 2009, 9, 2914-2920.

155. S. Lee, H. Chon, S. Y. Yoon, E. K. Lee, S. I. Chang, D. W. Lim and J. Choo, Nanoscale, 2012, 4, 124-129.

156. Y. Wang, S. Kang, A. Khan, G. Ruttner, S. Y. Leigh, M. Murray, S. Abeytunge, G. Peterson, M. Rajadhyaksha, S. Dintzis, S. Javid and J. T. Liu, Sci. Rep., 2016, 6, 21242.

157. S. Kang, Y. Wang, N. P. Reder and J. T. Liu, PloS One, 2016, 11, e0163473.

158. E. Tolstik, L. A. Osminkina, D. Akimov, M. B. Gongalsky, A. A. Kudryavtsev, V. Y. Timoshenko, R. Heintzmann, V. Sivakov and J. Popp, Int. J. Mol. Sci., 2016, 17, 1536.

159. M. Navas-Moreno, M. Mehrpouyan, T. Chernenko, D. Candas, M. Fan, J. J. Li, M. Yan and J. W. Chan, Sci. Rep., 2017, 7, 4471.

160. S. Y. Jung, S. Ahn, E. Seo and S. J. Lee, J. Synchr. Rad., 2013, 20, 324-331.

161. M. Salouti and F. Saghatchi, IET nanobiotechnol, 2017, 11, 604-611.

162. S. Shi, B. C. Fliss, Z. Gu, Y. Zhu, H. Hong, H. F. Valdovinos, R. Hernandez, S. Goel, H. Luo, F. Chen, T. E. Barnhart, R. J. Nickles, Z. P. Xu and W. Cai, Sci Rep, 2015, 5, 16930.

163. B. Cornelissen, S. Able, V. Kersemans, P. A. Waghorn, S. Myhra, K. Jurkshat, A. Crossley and K. A. Vallis, Biomaterials, 2013, 34, 1146-1154.

164. R. T. Branca, Y. M. Chen, V. Mouraviev, G. Galiana, E. R. Jenista, C. Kumar, C. Leuschner and W. S. Warren, Magn. Reson. Med. Sci., 2009, 61, 937-943.

165. C. Zhou, T. H. Tsai, D. C. Adler, H. C. Lee, D. W. Cohen, A. Mondelblatt, Y. Wang, J. L. Connolly and J. G. Fujimoto, Optics Lett., 2010, 35, 700-702.

166. L. Wang, X. Zhong, W. Qian, J. Huang, Z. Cao, Q. Yu, M. Lipowska, R. Lin, A. Wang, L. Yang and H. Mao, J. Magn. Reson. Imaging, 2014, 40, 1071-1081.

167. P. M. Ferguson, K. W. Feindel, A. Slocombe, M. MacKay, T. Wignall, B. Delahunt, R. D. Tilley and I. F. Hermans, PloS One, 2013, 8, e56572.

168. F. Zhang, L. Zhu, X. Huang, G. Niu and X. Chen, Mol. Imaging Biol., 2013, 15, 40-47.

169. A. Jafari, M. Salouti, S. F. Shayesteh, Z. Heidari, A. B. Rajabi, K. Boustani and A. Nahardani, Nanotechnol., 2015, 26, 075101.

170. D. L. Li, J. E. Tan, Y. Tian, S. Huang, P. H. Sun, M. Wang, Y. J. Han, H. S. Li, H. B. Wu, X. M. Zhang, Y. K. Xu and Q. S. Wang, Biomaterials, 2017, 147, 86-98. 
171. M. V. Yigit, S. K. Ghosh, M. Kumar, V. Petkova, A. Kavishwar, A. Moore and Z. Medarova, Oncogene, 2013, 32, 1530-1538.

172. H. Zheng, X. Li, C. Chen, J. Chen, J. Sun, S. Sun, L. Jin, J. Li, S. Sun and X. Wu, Int. J. Nanomed., 2016, 11, 5519-5529.

173. L. Hartsuiker, P. van Es, W. Petersen, T. G. van Leeuwen, L. W. M. M. Terstappen and C. Otto, J. Microscopy, 2011, 244, 187-193.

174. R. Choudhary, S. Patra, R. Madhuri and P. K. Sharma, Biosens. Bioelectron., 2017, 91, 472481.

175. T. R. Nayak, C. Andreou, A. Oseledchyk, W. D. Marcus, H. C. Wong, J. Massague and M. F. Kircher, Nanoscale, 2017, 9, 1110-1119.

176. F. Fay, L. Hansen, S. Hectors, B. L. Sanchez-Gaytan, Y. Zhao, J. Tang, J. Munitz, A. Alaarg, M. S. Braza, A. Gianella, S. A. Aaronson, T. Reiner, J. Kjems, R. Langer, F. J. M. Hoeben, H. M. Janssen, C. Calcagno, G. J. Strijkers, Z. A. Fayad, C. Perez-Medina and W. J. M. Mulder, Bioconj. Chem., 2017, 28, 1413-1421.

177. J. Xia, G. Feng, X. Xia, L. Hao and Z. Wang, Int J Nanomedicine, 2017, 12, 1803-1813.

178. G. Feng, L. Hao, C. Xu, H. Ran, Y. Zheng, P. Li, Y. Cao, Q. Wang, J. Xia and Z. Wang, Int. J. Nanomed., 2017, 12, 4647-4659.

179. T. Zhang, H. Cui, C. Y. Fang, K. Cheng, X. Yang, H. C. Chang and M. L. Forrest, Nanomedicine , 2015, 10, 573-587.

180. R. Bardhan, S. Lal, A. Joshi and N. J. Halas, Acc. Chem. Res., 2011, 44, 936-946.

181. R. M. Yang, C. P. Fu, J. Z. Fang, X. D. Xu, X. H. Wei, W. J. Tang, X. Q. Jiang and L. M. Zhang, Int. J. Nananomed., 2017, 12, 197-206.

182. T. K. Jain, S. P. Foy, B. Erokwu, S. Dimitrijevic, C. A. Flask and V. Labhasetwar, Biomaterials, 2009, 30, 6748-6756.

183. S. P. Foy, R. L. Manthe, S. T. Foy, S. Dimitrijevic, N. Krishnamurthy and V. Labhasetwar, ACS Nano, 2010, 4, 5217-5224.

184. Q. Quan, J. Xie, H. Gao, M. Yang, F. Zhang, G. Liu, X. Lin, A. Wang, H. S. Eden, S. Lee, G. Zhang and X. Chen, Mol. Pharm., 2011, 8, 1669-1676.

185. L. Yang, H. K. Sajja, Z. Cao, W. Qian, L. Bender, A. I. Marcus, M. Lipowska, W. C. Wood and Y. A. Wang, Theranostics, 2013, 4, 106-118.

186. F. Corsi, L. Fiandra, C. De Palma, M. Colombo, S. Mazzucchelli, P. Verderio, R. Allevi, A. Tosoni, M. Nebuloni, E. Clementi and D. Prosperi, ACS Nano, 2011, 5, 6383-6393.

187. M. Patitsa, K. Karathanou, Z. Kanaki, L. Tzioga, N. Pippa, C. Demetzos, D. A. Verganelakis, Z. Cournia and A. Klinakis, Sci. Rep., 2017, 7, 775.

188. J. S. Basuki, H. T. Duong, A. Macmillan, R. B. Erlich, L. Esser, M. C. Akerfeldt, R. M. Whan, M. Kavallaris, C. Boyer and T. P. Davis, ACS Nano, 2013, 7, 10175-10189.

189. T. Li, X. Shen, Y. Chen, C. Zhang, J. Yan, H. Yang, C. Wu, H. Zeng and Y. Liu, Int. J. Nanomed., 2015, 10, 4279-4291.

190. A. M. Fales, H. Yuan and T. Vo-Dinh, Langmuir, 2011, 27, 12186-12190.

191. A. M. Fales, H. Yuan and T. Vo-Dinh, Mol. Pharm., 2013, 10, 2291-2298.

192. S. Wang, Z. Dai, H. Ke, E. Qu, X. Qi, K. Zhang and J. Wang, Eur. J. Radiol., 2014, 83, 117122.

193. B. Li, P. Zhang, J. Du, X. Zhao and Y. Wang, Coll. Surf. B Biointerfaces, 2017, 154, 133141.

194. G. Yang, Z. Liu, Y. Li, Y. Hou, X. Fei, C. Su, S. Wang, Z. Zhuang and Z. Guo, Biomater. Sci., 2017, 5, 2048-2055.

195. Y. Wang, Y. Liu, H. Luehmann, X. Xia, P. Brown, C. Jarreau, M. Welch and Y. Xia, ACS Nano, 2012, 6, 5880-5888.

196. Y. Wang, K. C. Black, H. Luehmann, W. Li, Y. Zhang, X. Cai, D. Wan, S. Y. Liu, M. Li, P. Kim, Z. Y. Li, L. V. Wang, Y. Liu and Y. Xia, ACS Nano, 2013, 7, 2068-2077.

197. U. S. Dinish, G. Balasundaram, Y. T. Chang and M. Olivo, Sci. Rep., 2014, 4, 4075. 
198. J. Conde, N. Oliva and N. Artzi, Proc. Natl. Acad. Sci.USA, 2015, 112, E1278-1287.

199. S. Chattoraj, A. Amin, B. Jana, S. Mohapatra, S. Ghosh and K. Bhattacharyya, ChemPhysChem, 2016, 17, 253-259.

200. W. Chen, S. Zhang, Y. Yu, H. Zhang and Q. He, Adv Mater, 2016, 28, 8567-8585.

201. F. Chen, H. Hong, Y. Zhang, H. F. Valdovinos, S. Shi, G. S. Kwon, C. P. Theuer, T. E. Barnhart and W. Cai, ACS Nano, 2013, 7, 9027-9039.

202. E. Tolstik, L. A. Osminkina, C. Matthaus, M. Burkhardt, K. E. Tsurikov, U. A. Natashina, V. Y. Timoshenko, R. Heintzmann, J. Popp and V. Sivakov, Nanomedicine, 2016, 12, 19311940.

203. J. Su, H. Sun, Q. Meng, P. Zhang, Q. Yin and Y. Li, Theranostics, 2017, 7, 523-537.

204. F. Zhou, B. Feng, H. Yu, D. Wang, T. Wang, J. Liu, Q. Meng, S. Wang, P. Zhang, Z. Zhang and Y. Li, Theranostics, 2016, 6, 679-687.

205. J. H. Choi and B. K. Oh, J. Ind. Microbiol. Biotechnol., 2014, 24, 1291-1299.

206. S. Wang, P. Huang, L. Nie, R. Xing, D. Liu, Z. Wang, J. Lin, S. Chen, G. Niu, G. Lu and X. Chen, Adv. Mater., 2013, 25, 3055-3061.

207. Y. Liu, M. Xu, Q. Chen, G. Guan, W. Hu, X. Zhao, M. Qiao, H. Hu, Y. Liang, H. Zhu and D. Chen, Int. J. Nanomed., 2015, 10, 4747-4761.

208. L. Geng, Z. Wang, X. Jia, Q. Han, Z. Xiang, D. Li, X. Yang, D. Zhang, X. Bu, W. Wang, Z. $\mathrm{Hu}$ and Q. Fang, Theranostics, 2016, 6, 1261-1273.

209. Y. Du, X. Liang, Y. Li, T. Sun, Z. Jin, H. Xue and J. Tian, Mol. Pharm., 2017, 14, 39783986.

210. A. Mashal, B. Sitharaman, X. Li, P. K. Avti, A. V. Sahakian, J. H. Booske and S. C. Hagness, IEEE Trans Rehabil. Eng., 2010, 57, 1831-1834.

211. A. Al Faraj, A. P. Shaik and A. S. Shaik, Int. J. Nanomed., 2015, 10, 157-168.

212. L. Hou, X. Yang, J. Ren, Y. Wang, H. Zhang, Q. Feng, Y. Shi, X. Shan, Y. Yuan and Z. Zhang, Int. J. Nanomed., 2016, 11, 607-624.

213. X. Liang, W. Shang, C. Chi, C. Zeng, K. Wang, C. Fang, Q. Chen, H. Liu, Y. Fan and J. Tian, Cancer Lett., 2016, 383, 243-249.

214. B. M. Barth, R. Sharma, E. I. Altinoglu, T. T. Morgan, S. S. Shanmugavelandy, J. M. Kaiser, C. McGovern, G. L. Matters, J. P. Smith, M. Kester and J. H. Adair, ACS Nano, 2010, 4, 1279-1287.

215. B. M. Barth, S. S. Shanmugavelandy, J. M. Kaiser, C. McGovern, E. I. Altinoglu, J. K. Haakenson, J. A. Hengst, E. L. Gilius, S. A. Knupp, T. E. Fox, J. P. Smith, T. M. Ritty, J. H. Adair and M. Kester, ACS Nano, 2013, 7, 2132-2144.

216. L. G. Delogu, G. Vidili, E. Venturelli, C. Menard-Moyon, M. A. Zoroddu, G. Pilo, P. Nicolussi, C. Ligios, D. Bedognetti, F. Sgarrella, R. Manetti and A. Bianco, Proc. Natl. Acad. SCi. USA, 2012, 109, 16612-16617.

217. S. B. Rizvi, S. Rouhi, S. Taniguchi, S. Y. Yang, M. Green, M. Keshtgar and A. M. Seifalian, Int. J. Nanomed., 2014, 9, 1323-1337.

218. M. Zhou, G. Ku, L. Pageon and C. Li, Nanoscale, 2014, 6, 15228-15235.

219. J. Liu, J. Han, Z. Kang, R. Golamaully, N. Xu, H. Li and X. Han, Nanoscale, 2014, 6, 57705776.

220. L. Yang, J. Cheng, Y. Chen, S. Yu, F. Liu, Y. Sun, Y. Chen and H. Ran, Sci. Rep., 2017, 7, 45213.

221. J. Peng, M. Dong, B. Ran, W. Li, Y. Hao, Q. Yang, L. Tan, K. Shi and Z. Qian, ACS Appl. Mater. Interfaces, 2017, 9, 13875-13886.

222. L. Zhou, T. Yang, J. Wang, Q. Wang, X. Lv, H. Ke, Z. Guo, J. Shen, Y. Wang, C. Xing and H. Chen, Theranostics, 2017, 7, 764-774.

223. H. Jung, K. M. Park, J. A. Yang, E. J. Oh, D. W. Lee, K. Park, S. H. Ryu, S. K. Hahn and K. Kim, Biomaterials, 2011, 32, 7687-7694. 
224. C. Yue, P. Liu, M. Zheng, P. Zhao, Y. Wang, Y. Ma and L. Cai, Biomaterials, 2013, 34, 6853-6861.

225. J. Li, P. Cai, A. Shalviri, J. T. Henderson, C. He, W. D. Foltz, P. Prasad, P. M. Brodersen, Y. Chen, R. DaCosta, A. M. Rauth and X. Y. Wu, ACS nano, 2014, 8, 9925-9940.

226. A. Shalviri, W. D. Foltz, P. Cai, A. M. Rauth and X. Y. Wu, J. Contr. Release, 2013, 167, 11-20.

227. H. Koo, K. H. Min, S. C. Lee, J. H. Park, K. Park, S. Y. Jeong, K. Choi, I. C. Kwon and K. Kim, J. Contr. Release, 2013, 172, 823-831.

228. L. N. Turino, M. R. Ruggiero, R. Stefania, J. C. Cutrin, S. Aime and S. Geninatti Crich, Bioconj. Chem., 2017, 28, 1283-1290.

229. Y. Zhao, Z. H. Houston, J. D. Simpson, L. Chen, N. L. Fletcher, A. V. Fuchs, I. Blakey and K. J. Thurecht, Mol. Pharm., 2017, 14, 3539-3549.

230. J. Choi, H. Kim and Y. Choi, Quant. Imaging Med. Surg., 2015, 5, 656-664.

231. Y. Li, H. T. Duong, S. Laurent, A. MacMillan, R. M. Whan, L. V. Elst, R. N. Muller, J. Hu, A. Lowe, C. Boyer and T. P. Davis, Adv. Healthc. Mater., 2015, 4, 148-156.

232. A. Z. Abbasi, P. Prasad, P. Cai, C. He, W. D. Foltz, M. A. Amini, C. R. Gordijo, A. M. Rauth and X. Y. Wu, J. Contr. Release, 2015, 209, 186-196.

233. C. Perez-Medina, D. Abdel-Atti, J. Tang, Y. Zhao, Z. A. Fayad, J. S. Lewis, W. J. Mulder and T. Reiner, Nat. Commun., 2016, 7, 11838.

234. D. Gao, J. Gao, M. Xu, Z. Cao, L. Zhou, Y. Li, X. Xie, Q. Jiang, W. Wang and J. Liu, Mol. Pharm., 2017, 14, 984-998.

235. M. Orecchioni, C. Menard-Moyon, L. G. Delogu and A. Bianco, Adv. Drug Deliv. Rev., 2016, 105, 163-175.

236. S. Shi, K. Yang, H. Hong, H. F. Valdovinos, T. R. Nayak, Y. Zhang, C. P. Theuer, T. E. Barnhart, Z. Liu and W. Cai, Biomaterials, 2013, 34, 3002-3009.

237. L. G. Delogu, S. M. Stanford, E. Santelli, A. Magrini, A. Bergamaschi, K. Motamedchaboki, N. Rosato, T. Mustelin, N. Bottini and M. Bottini, J. Nanosci. Nanotechnol., 2010, 10, 5293-5301.

238. J. Bartelmess, E. De Luca, A. Signorelli, M. Baldrighi, M. Becce, R. Brescia, V. Nardone, E. Parisini, L. Echegoyen, P. P. Pompa and S. Giordani, Nanoscale, 2014, 6, 13761-13769.

239. A. G. Cuenca, H. Jiang, S. N. Hochwald, M. Delano, W. G. Cance and S. R. Grobmyer, Cancer, 2006, 107, 459-466.

240. C. Murugan, K. Rayappan, R. Thangam, R. Bhanumathi, K. Shanthi, R. Vivek, R. Thirumurugan, A. Bhattacharyya, S. Sivasubramanian, P. Gunasekaran and S. Kannan, Sci. Rep., 2016, 6, 34053.

241. M. Orecchioni, D. Bedognetti, L. Newman, C. Fuoco, F. Spada, W. Hendrickx, F. M. Marincola, F. Sgarrella, A. F. Rodrigues, C. Menard-Moyon, G. Cesareni, K. Kostarelos, A. Bianco and L. G. Delogu, Nat. Commun., 2017, 8, 1109.

242. S. Di Palma and B. Bodenmiller, Curr. Opin. Biotechnol., 2015, 31, 122-129. 


\section{Figure captions}

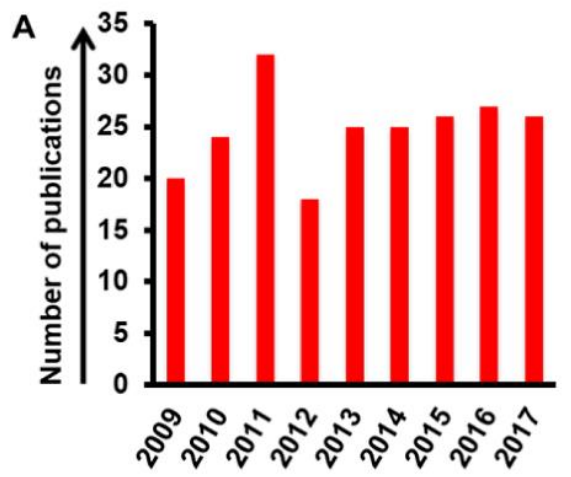

B

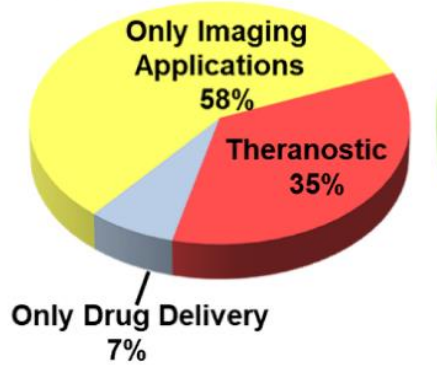

C

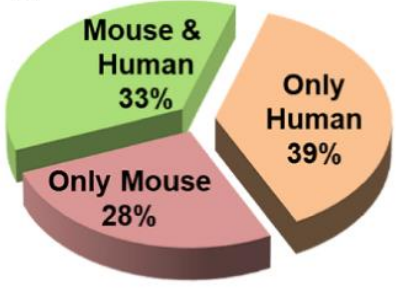

Fig. 1. Status of applications used on BC studies. A) Analysis of publications in the last 9 years (2009 to 2017). B) Relative percentages of publications for imaging, theranostic and drug delivery applications. C) Species examined in each publications (human, mouse and combination of human and mouse).

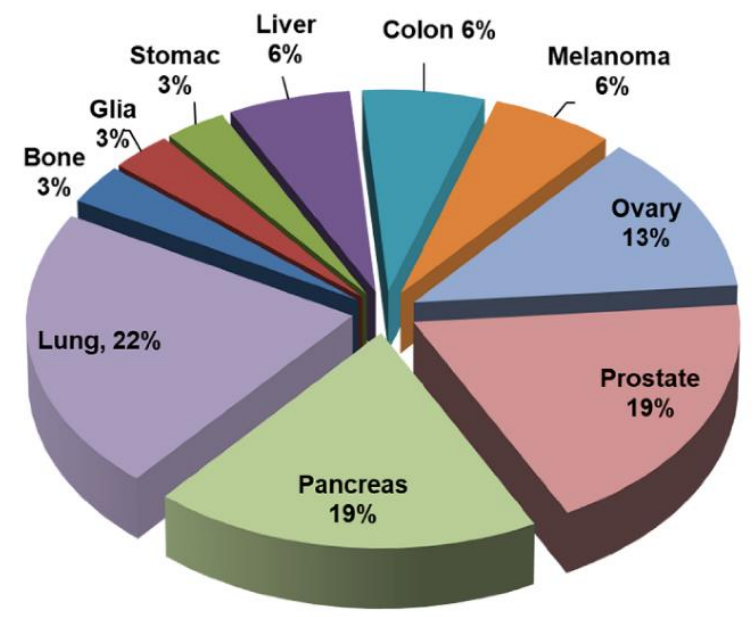

Fig. 2. Percentage of publications focusing on other types of cancer together with BC. 


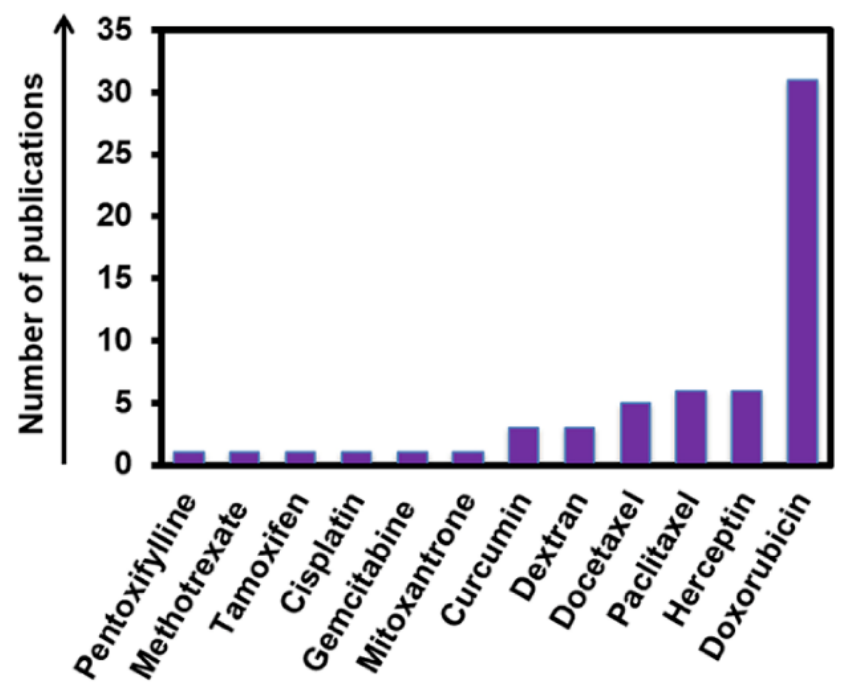

Fig. 3. Conjugated drugs to nanomaterials. Number publications in the last 9 years based on the type of drugs conjugated to nanomaterials and nanoparticles to fight $\mathrm{BC}$.

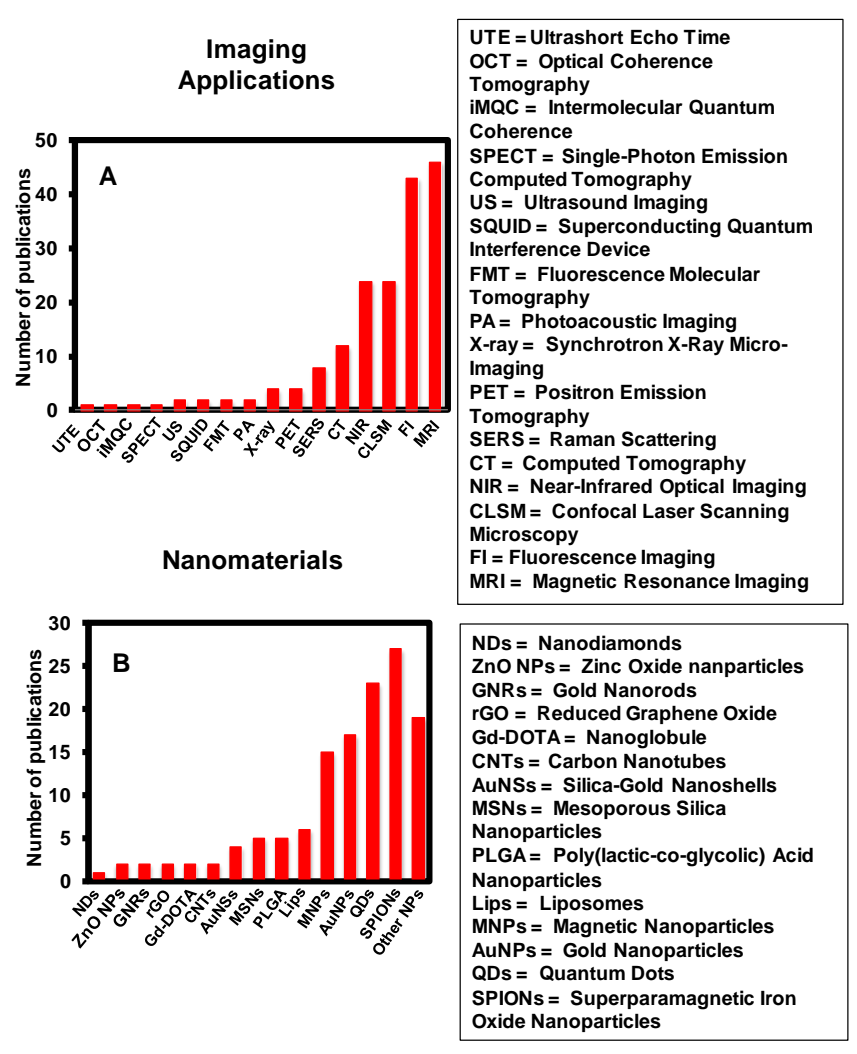

Fig. 4. Overview on different types of techniques and nanomaterials for imaging. A) Analysis of the number of publications based on the different kind of Imaging Applications for BC. B) Types of nanomaterials used for imaging. 


\begin{tabular}{|c|c|}
\hline THERANOSTIC MATERIAL & Abbreviation \\
\hline Magnetic Nanoparticles & MNPs \\
\hline $\begin{array}{l}\text { Calcium Phosphosilicate } \\
\text { Composite Nanoparticles }\end{array}$ & CPSNPS \\
\hline Liposomes & Lips \\
\hline Gold Nanoparticles & AuNPs \\
\hline Gold Nanorods & GNRs \\
\hline Gold Nanoshells & AuNSs \\
\hline Carbon Nanotubes & CNTs \\
\hline $\begin{array}{l}\text { Hydrotropic oligomer- } \\
\text { conjugated nanoparticles }\end{array}$ & HO-CNPs \\
\hline Nanoparticles & NPs \\
\hline Mesoporous Silica Nanoparticles & MSNs \\
\hline Quantum Dots & QDs \\
\hline Copper(II) sulfide nanoparticles & CuS NPs \\
\hline $\begin{array}{l}\text { Superparamagnetic Iron Oxide } \\
\text { Nanoparticles }\end{array}$ & SPIONs \\
\hline Tungsten oxide Nanoparticles & wO3-x \\
\hline $\begin{array}{l}\text { Thiol-functionalized hyaluronic } \\
\text { acid }\end{array}$ & HS-HA \\
\hline $\begin{array}{l}\text { Mesoporous Magnetic Gold } \\
\text { "nanoclusters" }\end{array}$ & MMGNCs \\
\hline Heparinefolic acid nanoparticles & HFNPs \\
\hline Reduced Graphene Oxide & rGo \\
\hline Carbon Nano-Onions & CNOs \\
\hline
\end{tabular}

Fig. 5. List and acronyms of nanomaterials used as theranostic in the treatment of BC. 


\section{Graphical Abstract}

Different nanomaterials have been developed to fight against breast cancer.

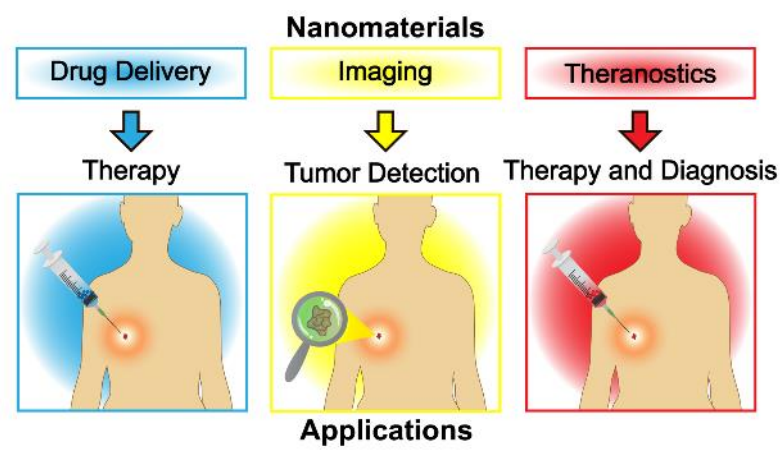


How can nanotechnology help the fight against breast cancer?

Elisabetta Avitabile, ${ }^{1}$ Davide Bedognetti, ${ }^{2}$ Gianni Ciofani,, 34 Alberto Bianco, ${ }^{3 *}$ and Lucia Gemma Delogu, ${ }^{1,6,7^{*}}$

\section{ELECTRONIC SUPPLEMENTARY INFORMATION}




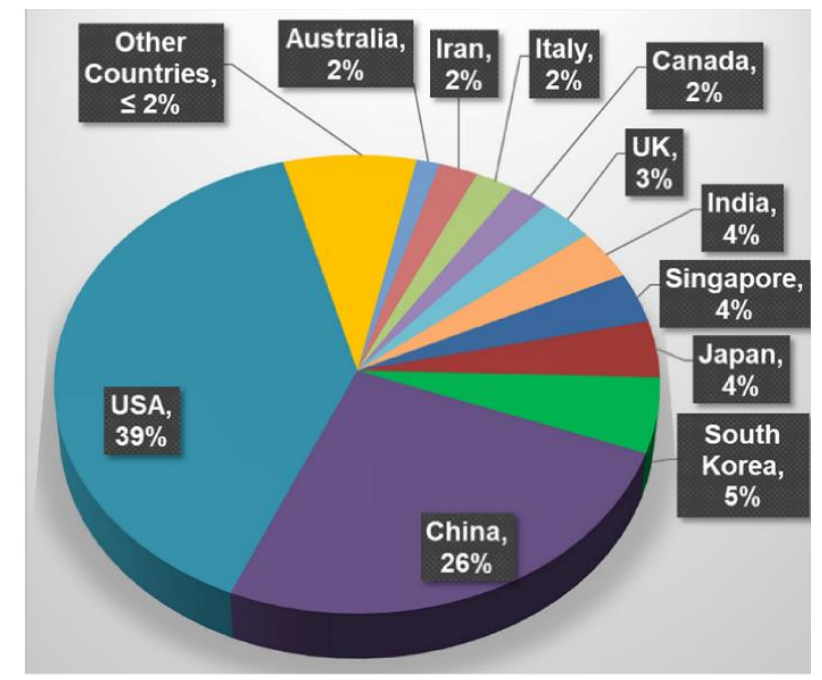

Fig. S1. Percentage of publications carried out on nanomaterials fight against BC per Countries. The piece of the cake in yellow, reported the studies in a percentage of $<2 \%$ conducted in other countries such as: New Zealand, Greece, Brazil, Taiwan, Malaysia, Riyadh-Saudi Arabia, The Netherlands, Israel, Germany, France, Georgia, Poland. 
Table S1: Drug delivery

\begin{tabular}{|c|c|c|c|c|c|}
\hline Material & Drug & Imaging & Model & Cell type & Ref. $^{*}$ \\
\hline $\begin{array}{l}\text { Poly(lactic-co- } \\
\text { lycolic) Acid } \\
\text { Nanoparticles }\end{array}$ & $\begin{array}{l}\text { Dextran } \\
(\mathrm{T}-40)\end{array}$ & $\begin{array}{l}\text { Fluorescence } \\
\text { imaging }\end{array}$ & $\begin{array}{l}\text { In vivo / In vitro } \\
\text { (MCF-7 cells) }\end{array}$ & & [42] \\
\hline $\begin{array}{l}\text { Poly(lactic-co- } \\
\text { glycolic) Acid } \\
\text { Nanoparticles }\end{array}$ & Doxorubicin & CLSM & $\begin{array}{l}\text { In vivo / In vitro } \\
\text { (C127I cells) }\end{array}$ & & [22] \\
\hline $\begin{array}{c}\text { Paclitaxel } \\
\text { Nanoparticles }\end{array}$ & Paclitaxel & $\begin{array}{l}\text { Fluorescence } \\
\text { imaging }\end{array}$ & $\begin{array}{c}\text { In vivo } \\
\text { (MCF-7 cells) }\end{array}$ & & [36] \\
\hline $\begin{array}{c}\text { Paclitaxel } \\
\text { Nanoparticles }\end{array}$ & Paclitaxel & $\begin{array}{l}\text { CLSM, } \\
\text { NIR }\end{array}$ & $\begin{array}{l}\text { In vivo / Intro } \\
\text { (MCF-7 cells) }\end{array}$ & & [35] \\
\hline $\begin{array}{l}\text { FeCo/Graphitic } \\
\text { Carbon Shell } \\
\text { Nanocrystals }\end{array}$ & Doxorubicin & $\begin{array}{l}\text { MRI, } \\
\text { NIR }\end{array}$ & $\begin{array}{c}\text { In vitro } \\
\text { (MCF-7 cells) }\end{array}$ & & [23] \\
\hline $\begin{array}{l}\text { Superparamagnetic } \\
\text { Iron Oxide } \\
\text { Nanoparticles }\end{array}$ & Doxorubicin & CLSM & $\begin{array}{c}\text { In vitro } \\
\text { (MCF7 cells) }\end{array}$ & & [24] \\
\hline Liposomes & Doxorubicin & $\begin{array}{l}\text { CLSM, } \\
\text { Fluorescence } \\
\text { imaging }\end{array}$ & $\begin{array}{c}\text { In vivo / In vitro / } \\
\text { Ex vivo } \\
\text { (MDA-MB-231 } \\
\text { cells) } \\
\end{array}$ & & [71] \\
\hline $\begin{array}{l}\text { Mesoporous Silica } \\
\text { Nanoparticles }\end{array}$ & Paclitaxel & CLSM & $\begin{array}{c}\text { In vitro } \\
\text { (MDA-MB-231, } \\
\text { MDA-MB-468) }\end{array}$ & & [38] \\
\hline $\begin{array}{l}\text { Poly(lactic-co- } \\
\text { glycolic) Acid } \\
\text { Nanoparticles }\end{array}$ & Curcumin & CLSM & $\begin{array}{c}\text { In vitro } \\
\text { (MDA-MB-231 } \\
\text { cells) }\end{array}$ & & [39] \\
\hline $\begin{array}{l}\text { Mesoporous Silica } \\
\text { Nanoparticles }\end{array}$ & $\begin{array}{c}\text { Antibody (Her2-neu } \\
\text { Herceptin) }\end{array}$ & $\begin{array}{l}\text { MRI, } \\
\text { CLSM }\end{array}$ & $\begin{array}{c}\text { In vitro } \\
\text { (SKBR-3 cells) }\end{array}$ & & [28] \\
\hline DNA Origami & Doxorubicin & $\begin{array}{l}\text { Fluorescence } \\
\text { imaging }\end{array}$ & $\begin{array}{c}\text { In vivo / Ex vivo } \\
\text { (MDA-MB-231 } \\
\text { cells) }\end{array}$ & & [21] \\
\hline $\begin{array}{l}\text { Gold Nanorods and } \\
\text { Gold Nanoparticles }\end{array}$ & Docetaxel & CLSM & $\begin{array}{c}\text { In vitro } \\
\text { (MCF7 and } \\
\text { B16F10 cells) }\end{array}$ & & [44] \\
\hline $\begin{array}{l}\text { PLGA-TPGS } \\
\text { Nnanoparticles }\end{array}$ & Docetaxel & CLSM & $\begin{array}{c}\text { In vivo / In vitro } \\
\text { (MCF-7/TXT } \\
\text { cells) }\end{array}$ & & [45] \\
\hline $\begin{array}{c}\text { Iron-Oxide } \\
\text { Nanoparticles }\end{array}$ & Peptides & CLSM & $\begin{array}{c}\text { In vivo } \\
\text { (MCF10CA1a } \\
\text { model) }\end{array}$ & $\theta$ & [8] \\
\hline $\begin{array}{l}\text { Solid Polymer-Lipid } \\
\text { Nanoparticles }\end{array}$ & $\begin{array}{l}\text { Ibuprofen, } \\
\text { Naproxen }\end{array}$ & $\begin{array}{l}\text { Fluorescence } \\
\text { imaging }\end{array}$ & $\begin{array}{c}\text { In vitro / In vivo / } \\
\text { Ex vivo } \\
\text { (EMT6, MDA- } \\
\text { MB-231, DU145 } \\
\text { cells) }\end{array}$ & & [9] \\
\hline
\end{tabular}

* The reference numbers in the table refer to those in the main text. 
Table S2: Imaging applications

\begin{tabular}{|c|c|c|c|c|c|}
\hline Material & $\begin{array}{l}\text { Conjugated } \\
\text { molecules }\end{array}$ & Imaging & Model & Cell type & Ref.* \\
\hline $\begin{array}{l}\text { Poly(lactic-co- } \\
\text { glycolic) Acid } \\
\text { Nanoparticles }\end{array}$ & Rhodamine-6G & $\begin{array}{l}\text { Fluorescence } \\
\text { imaging }\end{array}$ & $\begin{array}{c}\text { In vitro } \\
\text { (MDA-MB-231 } \\
\text { cells) }\end{array}$ & & [80] \\
\hline Quantum Dots & $\begin{array}{c}\text { Poly(lactide)-Vitamin } \\
\text { E TPGS }\end{array}$ & CLSM & $\begin{array}{c}\text { In vitro } \\
\text { (MCF-7 cells) }\end{array}$ & & [120] \\
\hline $\begin{array}{l}\text { Superparamagnetic } \\
\text { Iron Oxide } \\
\text { Nanoparticles }\end{array}$ & $\begin{array}{l}\text { NIR Dye (Cy5.5), } \\
\text { Peptides }\end{array}$ & MRI, NIR & $\begin{array}{c}\text { In vivo / In vitro / } \\
\text { Ex vivo } \\
\text { (BT-20 cells) }\end{array}$ & & [79] \\
\hline Liposomes & lodine & CT & $\begin{array}{l}\text { In vivo / In vitro } \\
\text { (R3230AC cells) }\end{array}$ & & [144] \\
\hline Gold Nanoparticles & $\begin{array}{l}\text { Sodium Dodecyl } \\
\text { Sulphate, } \\
\text { Polyethylene Glycol }\end{array}$ & CLSM & $\begin{array}{c}\text { In vitro } \\
\text { (Hs578T cells) }\end{array}$ & & [121] \\
\hline $\begin{array}{l}\text { Hollow Gold } \\
\text { Nanospheres }\end{array}$ & $\begin{array}{l}\text { Dihydrolipoic Acid, } \\
\text { Raman Reporter, } \\
\text { Anti-rabbit IgG }\end{array}$ & $\begin{array}{l}\text { SERS, } \\
\text { Fluorescence } \\
\text { imaging }\end{array}$ & $\begin{array}{c}\text { In vitro } \\
\text { (MCF-7 cells) }\end{array}$ & & [81] \\
\hline $\begin{array}{l}\text { Superparamagnetic } \\
\text { Iron Oxide } \\
\text { Nanoparticles }\end{array}$ & $\begin{array}{l}\text { Luteinizing Hormone } \\
\text { Releasing Hormone }\end{array}$ & iMQC & $\begin{array}{l}\text { In vivo / In vitrio } \\
\text { (MDA-MB-435, } \\
\text { PC-3 cells) }\end{array}$ & & [164] \\
\hline $\begin{array}{c}\text { Magnetic } \\
\text { Nanoparticles and } \\
\text { Golden Carbon } \\
\text { Nanotubes }\end{array}$ & $\begin{array}{l}\text { Amino-Terminal } \\
\text { Fragment of the } \\
\text { Urokinase } \\
\text { Plasminogen } \\
\text { Activator, } \\
\text { Polyethylene Glycol, } \\
\text { Folic Acid } \\
\end{array}$ & $\begin{array}{l}\text { Fluorescence } \\
\text { imaging }\end{array}$ & $\begin{array}{c}\text { In vivo / In vitro } \\
\text { (MDA-MB-231 } \\
\text { cells) }\end{array}$ & & [82] \\
\hline $\begin{array}{c}\text { Magnetic } \\
\text { Nanoparticles }\end{array}$ & $\begin{array}{c}\text { Urokinase } \\
\text { Plasminogen } \\
\text { Activator, NIR Dye } \\
\text { (Cy5.5) }\end{array}$ & $\begin{array}{l}\text { MRI, NIR, } \\
\text { Fluorescence } \\
\text { imaging }\end{array}$ & $\begin{array}{l}\text { In vivo / In vitro } \\
\text { (4T1, T47D } \\
\text { cells) }\end{array}$ & & [83] \\
\hline Quantum Dots & $\begin{array}{c}\text { Antibody (AVE- } \\
\text { 1642), Small } \\
\text { molecule, } \\
\text { Fluorophore (Alexa } \\
680 \text { ) }\end{array}$ & $\begin{array}{c}\text { CLSM, } \\
\text { Fuorescence } \\
\text { imaging }\end{array}$ & $\begin{array}{l}\text { In vivo / In vitro } \\
\text { (MCF-7 cells) }\end{array}$ & & [122] \\
\hline Gold Nanorods & $\begin{array}{l}\text { 14-Amino Acid } \\
\text { Peptide Bombesin }\end{array}$ & $\begin{array}{l}\text { Fluorescence } \\
\text { imaging }\end{array}$ & $\begin{array}{c}\text { In vitro } \\
\text { (PC-3, T-47D } \\
\text { cells) }\end{array}$ & & [84] \\
\hline
\end{tabular}




\begin{tabular}{|c|c|c|c|c|}
\hline Quantum Dots & $\begin{array}{c}\text { Antibodes } \\
\text { (anti-CD44v6, anti- } \\
\text { CD24) }\end{array}$ & $\begin{array}{l}\text { Fluorescence } \\
\text { imaging }\end{array}$ & $\begin{array}{c}\text { In vitro } \\
\text { (Tumor Tissue) }\end{array}$ & [85] \\
\hline Gold Nanoparticles & $\begin{array}{l}\text { Bovine Serum } \\
\text { Albumin }\end{array}$ & $\begin{array}{l}\text { Fluorescence } \\
\text { imaging }\end{array}$ & $\begin{array}{c}\text { In vitro } \\
\text { (MCF-7 cells) }\end{array}$ & [5] \\
\hline $\begin{array}{l}\text { Mesoporous Silica } \\
\text { Nanoparticles }\end{array}$ & $\begin{array}{c}\text { Antibody } \\
\text { (anti-EGFR) }\end{array}$ & $\begin{array}{l}\text { Fluorescence } \\
\text { imaging }\end{array}$ & $\begin{array}{c}\text { In vitro } \\
\text { (MCF-7 cells) }\end{array}$ & [86] \\
\hline Gold Nanoparticles & $\begin{array}{c}\text { Antibody } \\
\text { (anti-EGFR) }\end{array}$ & $\begin{array}{l}\text { Fluorescence } \\
\text { imaging }\end{array}$ & $\begin{array}{c}\text { In vitro } \\
\text { (A431, 270- } \\
\text { GBM, H2224, } \\
\text { MDAMB-453 } \\
\text { cells) } \\
\end{array}$ & [87] \\
\hline $\begin{array}{l}\text { Silica-Gold } \\
\text { Nanoshells }\end{array}$ & $\begin{array}{l}\text { Polyethylene Glycol, } \\
\text { P-mercaptoaniline }\end{array}$ & SERS & $\begin{array}{c}\text { In vitro } \\
\text { (MCF-7 cells) }\end{array}$ & [154] \\
\hline $\begin{array}{l}\text { Silica-Gold } \\
\text { Nanoshells }\end{array}$ & $\begin{array}{l}\text { Polyethylene Glycol, } \\
\text { Antibody (anti-HER2) }\end{array}$ & $\begin{array}{l}\text { NIR, MRI, } \\
\text { Fluorescence } \\
\text { imaging }\end{array}$ & $\begin{array}{l}\text { In vivo / In vitro } \\
\text { (BT474AZ, } \\
\text { MDAMB231 } \\
\text { cells) }\end{array}$ & [56] \\
\hline Quantum Dots & $\begin{array}{c}\text { Prtein A, Antibody } \\
\text { (anti-CXCR4, anti- } \\
\text { HER2), } \\
\text { Polyethylene Glycol }\end{array}$ & $\begin{array}{l}\text { Fluorescence } \\
\text { imaging }\end{array}$ & $\begin{array}{c}\text { In vitro } \\
\text { (KPL-4 cells })\end{array}$ & [88] \\
\hline $\begin{array}{l}\text { Silica-Gold } \\
\text { Nanoshells }\end{array}$ & - & OCT & $\begin{array}{c}\text { Ex vivo } \\
\text { (Tumor Tissue) }\end{array}$ & [165] \\
\hline $\begin{array}{l}\text { Gold-Gold Sulfide } \\
\text { Nanoparticles }\end{array}$ & $\begin{array}{c}\text { Antibodies } \\
\text { (anti-HER2, anti-lgG) }\end{array}$ & CLSM & $\begin{array}{c}\text { In vitro } \\
\text { (SK-BR-3 cells) }\end{array}$ & [123] \\
\hline $\begin{array}{l}\text { Superparamagnetic } \\
\text { Iron Oxide } \\
\text { Nanoparticles }\end{array}$ & $\begin{array}{l}\text { Poly2-hydroxyethyl } \\
\text { Aspartamide, } \\
\text { Antibody (HER2/neu) }\end{array}$ & MRI & $\begin{array}{c}\text { In vitro } \\
\text { (H520, SKBR-3 } \\
\text { cells) }\end{array}$ & [57] \\
\hline $\begin{array}{c}\text { Magnetic } \\
\text { Nanoparticles }\end{array}$ & $\begin{array}{c}\text { Oleic Acid, } \\
\text { Polyethylene glycol, } \\
\text { Antibodies } \\
\text { (IgG, anti-HER-2) }\end{array}$ & $\begin{array}{l}\text { MRI, } \\
\text { CLSM }\end{array}$ & $\begin{array}{c}\text { In vitro } \\
\text { (MCF-7 cells) }\end{array}$ & [58] \\
\hline Quantum Dots & Polystyrene Polymer & $\begin{array}{l}\text { Fluorescence } \\
\text { imaging }\end{array}$ & $\begin{array}{c}\text { In vitro } \\
\text { (MCF-7 cells) }\end{array}$ & [89] \\
\hline Quantum Dots & $\begin{array}{c}\text { Antibody } \\
\text { (anti-PAR1) }\end{array}$ & $\begin{array}{l}\text { Fluorescence } \\
\text { imaging }\end{array}$ & $\begin{array}{l}\text { In vivo / In vitro } \\
\text { (KPL-4 cells) }\end{array}$ & [90] \\
\hline
\end{tabular}




\begin{tabular}{|c|c|c|c|c|c|}
\hline $\begin{array}{l}\text { Superparamagnetic } \\
\text { Iron Oxide } \\
\text { Nanoparticles }\end{array}$ & $\begin{array}{l}\text { Polylactic acid, } \\
\text { D- } \alpha-\text { Tocopherol } \\
\text { Polyethylene glycol } \\
1000 \text { Succinate }\end{array}$ & MRI & $\begin{array}{l}\text { In vivo / In vitro } \\
\text { (MCF-7 cells) }\end{array}$ & & [59] \\
\hline $\begin{array}{c}\text { Polylactic-co-glycolic } \\
\text { Acid Nanoparticles }\end{array}$ & $\begin{array}{c}\text { Nanoparticles, } \\
\text { Gadolinium- } \\
\text { Diethylenetriamine } \\
\text { Penta-Acetic Acid }\end{array}$ & MRI & $\begin{array}{l}\text { In vivo / In vitro } \\
\text { (MCF-7 cells) }\end{array}$ & & [60] \\
\hline Quantum Dots & $\begin{array}{c}\text { Polyethylene Glycol } \\
\text { Phosphatidylethanol } \\
\text { amine, Antibody } \\
\text { (anti-nucleosome } \\
\text { 2C5) }\end{array}$ & NIR & $\begin{array}{l}\text { In vivo / Ex vivo } \\
\text { (4T1, B16F10 } \\
\text { cells) }\end{array}$ & & [135] \\
\hline $\begin{array}{l}\text { Superparamagnetic } \\
\text { Iron Oxide } \\
\text { Nanoparticles }\end{array}$ & - & MRI & $\begin{array}{c}\text { In vivo } \\
\text { (Tumor Tissue) }\end{array}$ & & [54] \\
\hline $\begin{array}{l}\text { Superparamagnetic } \\
\text { Iron Oxide } \\
\text { Nanoparticles }\end{array}$ & - & $\begin{array}{l}\text { MRI, } \\
\text { CT }\end{array}$ & $\begin{array}{c}\text { In vivo } \\
\text { (Tumor Tissue) }\end{array}$ & & [145] \\
\hline $\begin{array}{l}\text { Perfluorocarbon } \\
\text { Nanoparticles }\end{array}$ & $\begin{array}{l}\text { NIR Peptides } \\
\text { (Cypate-cRGDfK } \\
\text { Cypate-C18) }\end{array}$ & NIR & $\begin{array}{l}\text { In vivo / Ex vivo } \\
\text { (4T1 cells) }\end{array}$ & & [136] \\
\hline $\begin{array}{l}\text { Poly(n-butyl } \\
\text { cyanoacrylate) } \\
\text { Nanocapsules }\end{array}$ & $\begin{array}{l}\text { Cyanine } \\
\text { (IR-768) }\end{array}$ & CLSM & $\begin{array}{c}\text { In vitro } \\
\text { (MCF-7 cells) }\end{array}$ & & [124] \\
\hline $\begin{array}{l}\text { Superparamagnetic } \\
\text { Iron Oxide } \\
\text { Nanoparticles }\end{array}$ & Free Folic Acid & MRI & $\begin{array}{l}\text { In vivo / In vitro } \\
\text { (MDA-MB-231 } \\
\text { cells) }\end{array}$ & & [61] \\
\hline $\begin{array}{l}\text { Silica-Gold } \\
\text { Nanoshells }\end{array}$ & $\begin{array}{l}\text { Polyethylene Glycol, } \\
\text { Antibodies (anti- } \\
\text { HER2/neu, anti-lgG) }\end{array}$ & NIR & $\begin{array}{c}\text { In vitro } \\
\text { (SK-BR-3, } \\
\text { HCC1419, } \\
\text { JIMT-1 cells) }\end{array}$ & & [137] \\
\hline Nanoglobules & $\begin{array}{l}\text { Peptide } \\
\text { (CLT1) }\end{array}$ & MRI & $\begin{array}{c}\text { In vivo / In vitro } \\
\text { (MDA-MB-231 } \\
\text { cells) }\end{array}$ & & [62] \\
\hline $\begin{array}{l}\text { Superparamagnetic } \\
\text { Iron Oxide } \\
\text { Nanoparticles }\end{array}$ & $\begin{array}{c}\text { D-a-Tocopheryl-co- } \\
\text { polyethylene glycol- } \\
1000 \text { succinate, } \\
\text { Copolymer } \\
\text { (Pluronic®F127) }\end{array}$ & MRI & $\begin{array}{l}\text { In vivo / In vitro } \\
\text { (MCF-7 cells) }\end{array}$ & & [63] \\
\hline Gold Nanoparticles & $\begin{array}{l}\text { Polyethylene Glycol, } \\
\text { Antibody (HER81) }\end{array}$ & SEM & $\begin{array}{c}\text { In vitro } \\
\text { (SK-BR-3 cells) }\end{array}$ & & [173] \\
\hline
\end{tabular}




\begin{tabular}{|c|c|c|c|c|c|}
\hline Liposomes & lodine & CT & $\begin{array}{l}\text { In vivo / In vitro } \\
\text { (4T1 cells) }\end{array}$ & & [146] \\
\hline $\begin{array}{c}\text { Magnetic } \\
\text { Nanoparticles }\end{array}$ & $\begin{array}{l}\text { Fluorophores } \\
\text { (Feridex, } \\
\text { Dextranase) }\end{array}$ & $\begin{array}{l}\text { MRI, } \\
\text { CLSM }\end{array}$ & $\begin{array}{l}\text { In vivo / In vitro } \\
\text { (MCF-7 cells) }\end{array}$ & & [125] \\
\hline $\begin{array}{c}\text { Magnetic } \\
\text { Nanoparticles }\end{array}$ & $\begin{array}{c}\text { Polyethylenimine, } \\
\text { Polyethylene Glycol, } \\
\text { siRNA }\end{array}$ & CLSM & $\begin{array}{c}\text { In vitro } \\
\text { (MCF-7, TC2 } \\
\text { cells) }\end{array}$ & & [126] \\
\hline $\begin{array}{l}\text { Upconversion } \\
\text { Nanoparticles }\end{array}$ & $\begin{array}{l}\text { Polyethyleneglycol, } \\
\text { Chlorin e6 }\end{array}$ & $\begin{array}{l}\text { NIR, } \\
\text { CLSM }\end{array}$ & $\begin{array}{l}\text { In vivo / In vitro } \\
\text { (4T1 cells })\end{array}$ & & [127] \\
\hline $\begin{array}{l}\text { Mesoporous Silica } \\
\text { Nanoparticles }\end{array}$ & NIR Dye & NIR & $\begin{array}{c}\text { In vivo } \\
\text { (4T1, luc- } \\
\text { D3H2LN MDA- } \\
\text { MB-23 cells) }\end{array}$ & & [138] \\
\hline $\begin{array}{c}\text { Magnetic } \\
\text { Nanoparticles }\end{array}$ & $\begin{array}{l}\text { 5-Aminolevulinic } \\
\text { Acid, } \\
\text { Indocyanine Green } \\
\text { Dye }\end{array}$ & $\begin{array}{l}\text { CT, } \\
\text { NIR }\end{array}$ & $\begin{array}{c}\text { In vivo } \\
\text { (Tumor Tissue) }\end{array}$ & & [139] \\
\hline Quantum Dots & $\begin{array}{c}\text { Antibodies } \\
\text { (anti-HER2, anti- } \\
\text { collagen IV) }\end{array}$ & $\begin{array}{c}\text { Fluorescence } \\
\text { imaging }\end{array}$ & $\begin{array}{c}\text { In vitro } \\
\text { (Tumor Tissue) }\end{array}$ & & [91] \\
\hline Gold Nanoparticles & $\begin{array}{l}\text { Polyethylene Glycol, } \\
\text { Antibodies } \\
\text { (anti-Her2) }\end{array}$ & CT & $\begin{array}{l}\text { In vivo / In vitro } \\
\text { (BT-474, MCF7 } \\
\text { cells) }\end{array}$ & & [147] \\
\hline $\begin{array}{c}\text { Superparamagnetic } \\
\text { Iron Oxide } \\
\text { Nanoparticles }\end{array}$ & - & MRI & $\begin{array}{c}\text { In vivo } \\
\text { (Breast tissue) }\end{array}$ & & [13] \\
\hline Quantum Dots & $\begin{array}{l}\text { Tetraethyl } \\
\text { Orthosilicate, } \\
\text { Antibody } \\
\text { (anti-EGFR) }\end{array}$ & $\begin{array}{c}\text { Fluorescence } \\
\text { imaging }\end{array}$ & $\begin{array}{c}\text { In vitro } \\
\text { (MDA-MB-435S, } \\
\text { SMMC-7721 } \\
\text { cells) }\end{array}$ & & [92] \\
\hline Liposomes & $\begin{array}{c}\text { Thioated } \\
\text { Oligonucleotide } \\
\text { Aptamer, E-selectin, } \\
\text { Polyethylene Glycol }\end{array}$ & $\begin{array}{c}\text { Fluorescence } \\
\text { imaging }\end{array}$ & $\begin{array}{c}\text { In vivo / In vitro } \\
\text { (MDA-MB-435S, } \\
\text { SMMC-7721 } \\
\text { cells) }\end{array}$ & & [93] \\
\hline $\begin{array}{c}\text { Polyß-L-malic Acid } \\
\text { Platform }\end{array}$ & $\begin{array}{l}\text { Antibody (anti- } \\
\text { HER2/neu), NIR Dye } \\
\text { (Alexa Fluor 680), } \\
\text { Polyethylene Glycol }\end{array}$ & CLSM & $\begin{array}{c}\text { In vivo / In vitro } \\
\text { (BT-474, SKBR- } \\
3, \text { MDA-MB- } \\
\text { 231, MDA-MB- } \\
\text { 435, MDAMB- } \\
468 \text { cells) }\end{array}$ & & [128] \\
\hline
\end{tabular}




\begin{tabular}{|c|c|c|c|c|c|}
\hline $\begin{array}{c}\text { Quantum Dots, } \\
\text { Superparamagnetic } \\
\text { Iron Oxide } \\
\text { Nanoparticles }\end{array}$ & $\begin{array}{l}\text { Polylactic Acid-d-a- } \\
\text { Tocopheryl } \\
\text { Polyethylene Glycol } \\
1000 \text { Succinate } \\
\text { Nanoparticles }\end{array}$ & $\begin{array}{c}\text { MRI, } \\
\text { CLSM, } \\
\text { Fluorescence } \\
\text { imaging }\end{array}$ & $\begin{array}{l}\text { In vivo / In vitro } \\
\text { (MCF-7 cells) }\end{array}$ & & [64] \\
\hline $\begin{array}{l}\text { Superparamagnetic } \\
\text { Iron Oxide } \\
\text { Nanoparticles }\end{array}$ & $\begin{array}{c}\text { Quantum Dots, } \\
\text { Superparamagnetic } \\
\text { Iron Oxide } \\
\text { Nanoparticles, } \\
\text { Antibody (anti Her2) }\end{array}$ & $\begin{array}{l}\text { SQUID, } \\
\text { Fluorescence } \\
\text { imaging }\end{array}$ & $\begin{array}{c}\text { In vivo / In vitro } \\
\text { (MCF-7, MDA- } \\
\text { MB-231, BT-474 } \\
\text { cells) }\end{array}$ & & [94] \\
\hline $\begin{array}{l}\text { Superparamagnetic } \\
\text { Iron Oxide } \\
\text { Nanoparticles }\end{array}$ & - & $\begin{array}{l}\text { MRI, } \\
\text { CT }\end{array}$ & $\begin{array}{c}\text { In vivo } \\
\text { (Breast tissue) }\end{array}$ & & [148] \\
\hline $\begin{array}{l}\text { Photoswitchable } \\
\text { Nanoparticles }\end{array}$ & $\begin{array}{l}\text { Antibody } \\
\text { (anti-Her2) }\end{array}$ & $\begin{array}{c}\text { NIR, } \\
\text { Fluorescence } \\
\text { imaging }\end{array}$ & $\begin{array}{c}\text { In vitro } \\
\text { (SK-BR-3 cells) }\end{array}$ & & [96] \\
\hline Quantum Dots & $\begin{array}{l}\text { Polyethyleneglycol, } \\
\text { Fatty Ester Matrix }\end{array}$ & $\begin{array}{l}\text { Fluorescence } \\
\text { imaging }\end{array}$ & $\begin{array}{c}\text { In vivo } \\
\text { (MDA435 cells) }\end{array}$ & & [95] \\
\hline Magnetic Nanocluster & Pyrenyl Hyalurone & MRI & $\begin{array}{l}\text { In vivo / In vitro } \\
\text { (MDA-MB-231 } \\
\text { cells) }\end{array}$ & & [65] \\
\hline Nanoglobule & - & MRI & $\begin{array}{c}\text { In vivo } \\
\text { (MDA-MB-231 } \\
\text { cells) }\end{array}$ & & [66] \\
\hline $\begin{array}{l}\text { Mesoporous Silica } \\
\text { Nanoparticles }\end{array}$ & NIR Dye (MDT) & NIR & $\begin{array}{c}\text { In vivo } \\
\text { (4T1 cells) }\end{array}$ & & [140] \\
\hline $\begin{array}{l}\text { Superparamagnetic } \\
\text { Iron Oxide } \\
\text { Nanoparticles }\end{array}$ & $\begin{array}{l}\text { Chitosan, } \\
\text { Polyethylene Glycol, } \\
\text { Antibody (Neu) }\end{array}$ & $\begin{array}{l}\text { MRI, } \\
\text { CLSM }\end{array}$ & $\begin{array}{c}\text { In vivo / In vitro / } \\
\text { Ex vivo } \\
\text { (MMC cells) }\end{array}$ & & [67] \\
\hline $\begin{array}{l}\text { Superparamagnetic } \\
\text { Iron Oxide } \\
\text { Nanoparticles }\end{array}$ & $\begin{array}{l}\text { Dimercaptosuccinic } \\
\text { Acid, } \\
\text { 2-Deoxy-d-Glucose }\end{array}$ & MRI & $\begin{array}{c}\text { In vitro } \\
\text { (MDA-MB-231 } \\
\text { cells) }\end{array}$ & & [68] \\
\hline $\begin{array}{c}\text { Magnetic } \\
\text { Nanoparticles }\end{array}$ & $\begin{array}{c}\text { Gold, } \\
\text { Lanthanidedoped } \\
\text { Rare-Earth } \\
\text { Nanocrystals, } \\
\text { Polyethylene Glycol }\end{array}$ & MRI & $\begin{array}{l}\text { In vivo } \\
\text { (4T1 cells) }\end{array}$ & & [69] \\
\hline
\end{tabular}




\begin{tabular}{|c|c|c|c|c|c|}
\hline $\begin{array}{c}\text { Multiwalled } \\
\text { Carbon Nanotubes }\end{array}$ & $\begin{array}{c}\text { Magnetite } \\
\text { Nanoparticles, } \\
\text { Polyethylene Glycol }\end{array}$ & CLSM & $\begin{array}{l}\text { In vivo / In vitro } \\
\text { (MCF7, MDA } \\
\text { MB231 cells) }\end{array}$ & & [129] \\
\hline $\begin{array}{c}\text { Magnetic } \\
\text { Nanoparticles }\end{array}$ & $\begin{array}{l}\text { Integrin ( } \alpha \vee \beta 3) \text {, } \\
\text { Amines (DTSSP) }\end{array}$ & $\begin{array}{l}\text { MRI, } \\
\text { FMT, } \\
\text { CT }\end{array}$ & $\begin{array}{l}\text { In vivo / Ex vivo } \\
\text { (4T1 cells) }\end{array}$ & & [70] \\
\hline $\begin{array}{l}\text { Poly(lactic-co- } \\
\text { glycolic) Acid } \\
\text { Nanoparticles }\end{array}$ & $\begin{array}{c}\text { Indocyanine Green, } \\
\text { Folic Acid }\end{array}$ & $\begin{array}{c}\text { NIR, } \\
\text { Fluorescence } \\
\text { Imaging }\end{array}$ & $\begin{array}{l}\text { In vivo / In vitro } \\
\text { (MCF7 cells) }\end{array}$ & & [97] \\
\hline $\begin{array}{l}\text { Poly(lactic-co- } \\
\text { glycolic) Acid } \\
\text { Nanoparticles }\end{array}$ & $\begin{array}{c}\text { Magnetic } \\
\text { Nanoparticles }\end{array}$ & $\begin{array}{l}\text { MRI, } \\
\text { US }\end{array}$ & $\begin{array}{l}\text { In vivo / In vitro } \\
\text { (VX2 cells) }\end{array}$ & & [71] \\
\hline Gold Nanoparticles & $\begin{array}{c}\text { Peptides } \\
\text { (p12, CRGDH) }\end{array}$ & CLSM & $\begin{array}{c}\text { In vitro } \\
\text { (MDA-MB-231, } \\
\text { MCF-7 cells) }\end{array}$ & & [130] \\
\hline Quantum Dots & $\begin{array}{c}\text { Antibody } \\
\text { (Anti-GRP78 scFv) }\end{array}$ & $\begin{array}{l}\text { Fluorescence } \\
\text { imaging }\end{array}$ & $\begin{array}{c}\text { In vitro } \\
\text { (MDA-MB-231 } \\
\text { cells) }\end{array}$ & & [98] \\
\hline Quantum Dots & $\begin{array}{c}\text { Antibody } \\
\text { (Anti-HER2) }\end{array}$ & $\begin{array}{c}\text { NIR, } \\
\text { MRI, } \\
\text { Fluorescence } \\
\text { imaging }\end{array}$ & $\begin{array}{l}\text { In vivo / In vitro } \\
\text { (KPL-4 cells) }\end{array}$ & & [99] \\
\hline Gold Nanoparticles & $\begin{array}{c}\text { Antibody } \\
\text { (CD24, CD44) }\end{array}$ & SERS & $\begin{array}{c}\text { In vitro } \\
\text { (MDA-MB-231 } \\
\text { cells) }\end{array}$ & & [155] \\
\hline Gold Nanoparticles & $\begin{array}{c}\text { Wheat-Germ } \\
\text { Agglutinin, } \\
\text { Polyethylene Glycol }\end{array}$ & $\mathrm{NIR}$ & $\begin{array}{l}\text { In vivo / In vitro } \\
\text { (BT549 cells) }\end{array}$ & & [141] \\
\hline $\begin{array}{c}\text { Magnetic } \\
\text { Nanoparticles }\end{array}$ & $\begin{array}{c}\text { Antibody } \\
\text { (Anti-HER2) }\end{array}$ & $\begin{array}{l}\text { MRI, } \\
\text { SQUID }\end{array}$ & $\begin{array}{l}\text { In vivo / In vitro } \\
\text { (MCF7 cells) }\end{array}$ & & [153] \\
\hline $\begin{array}{c}\text { Magnetic } \\
\text { Nanoparticles }\end{array}$ & $\begin{array}{l}\text { Fluorophores } \\
\text { (TRITC) }\end{array}$ & CLSM & $\begin{array}{l}\text { In vivo / In vitro } \\
\text { (MTGB cells) }\end{array}$ & & [131] \\
\hline $\begin{array}{c}\text { Magnetic } \\
\text { Nanoparticles }\end{array}$ & $\begin{array}{c}\text { 3-Aminopropyl } \\
\text { triethoxysilane, } \\
\text { Antibody } \\
\text { (Anti-HER2) }\end{array}$ & MRI & $\begin{array}{c}\text { In vivo / In vitro } \\
\text { (MDA-MB-231, } \\
\text { SKBR-3, MDA- } \\
\text { MB-453, MCF7, } \\
\text { 4T1 cells) }\end{array}$ & & [72] \\
\hline
\end{tabular}




\begin{tabular}{|c|c|c|c|c|c|}
\hline $\begin{array}{l}\text { Superparamagnetic } \\
\text { Iron Oxide } \\
\text { Nnanoparticles, } \\
\text { Liposomes }\end{array}$ & $\begin{array}{l}\text { Polyethylene Glycol, } \\
\text { Rhodamine-DHPE }\end{array}$ & $\begin{array}{c}\text { MRI, } \\
\text { Fluorescence } \\
\text { imaging }\end{array}$ & $\begin{array}{l}\text { In vivo / In vitro } \\
\text { (MDA-MB-453, } \\
\text { MCF-7 cells) }\end{array}$ & & [100] \\
\hline Quantum Dots & $\begin{array}{c}\text { Magnetic Beads, } \\
\text { Nucleolin Aptamer } \\
\text { AS1411 }\end{array}$ & $\begin{array}{l}\text { Fluorescence } \\
\text { imaging }\end{array}$ & $\begin{array}{c}\text { In vitro } \\
\text { (MCF-7 cells) }\end{array}$ & & [101] \\
\hline $\begin{array}{c}\text { Magnetic } \\
\text { Nanoparticles }\end{array}$ & $\begin{array}{l}\text { Dopamine- } \\
\text { Polyethylene Glycol }\end{array}$ & $\begin{array}{l}\text { Fluorescence } \\
\text { imaging }\end{array}$ & $\begin{array}{c}\text { In vitro } \\
\text { (MCF-7 cells) }\end{array}$ & & [102] \\
\hline Graphene Oxide & $\begin{array}{c}\text { Antibody } \\
\text { (Anti-HER2), } \\
\text { 111In-benzyl- } \\
\text { diethylenetriamine- } \\
\text { pentaacetic acid }\end{array}$ & SPECT & $\begin{array}{l}\text { In vivo / In vitro } \\
\text { (MDA-MB-231 } \\
\text { cells) }\end{array}$ & & [163] \\
\hline $\begin{array}{c}\text { Superparamagnetic } \\
\text { Iron Oxide } \\
\text { Nanoparticles }\end{array}$ & - & MRI & $\begin{array}{l}\text { In vivo } \\
\text { (4T1 cells) }\end{array}$ & & [167] \\
\hline Gold Nanoparticles & Dendrimers & $\begin{array}{l}\text { MRI, } \\
\text { CT }\end{array}$ & $\begin{array}{l}\text { In vivo / In vitro } \\
\text { (MCF7 cells) }\end{array}$ & & [149] \\
\hline $\begin{array}{c}\text { Superparamagnetic } \\
\text { Iron Oxide } \\
\text { Nanoparticles }\end{array}$ & - & MRI & $\begin{array}{l}\text { In vivo / In vitro } \\
\text { (4T1 cells) }\end{array}$ & & [168] \\
\hline $\begin{array}{c}\text { Magnetic } \\
\text { Nanoparticles }\end{array}$ & $\begin{array}{c}\text { MiRNA } \\
\text { (Anti miR-10b) }\end{array}$ & MRI & $\begin{array}{l}\text { In vivo / In vitro } \\
\text { (MDAMB-231 } \\
\text { cells) }\end{array}$ & & [171] \\
\hline Gold Nanoparticles & $\begin{array}{l}\text { Thioglycolic acid, } \\
\text { 6-Thioguanine, } \\
\text { 2-Mercaptoethanol, } \\
\text { 1-Propanthiol }\end{array}$ & X-Ray & $\begin{array}{c}\text { In vitro } \\
\text { (MDAMB-231 } \\
\text { cells) }\end{array}$ & & [160] \\
\hline $\begin{array}{l}\text { Mesoporous Silica } \\
\text { Nanoparticle }\end{array}$ & $\begin{array}{c}{ }^{64} \mathrm{Cu}, \\
\text { Antibody (TRC105) }\end{array}$ & $\begin{array}{l}\text { PET, } \\
\text { NIR }\end{array}$ & $\begin{array}{l}\text { In vivo / In vitro } \\
\text { (4T1 cells) }\end{array}$ & & [142] \\
\hline $\begin{array}{c}\text { Magnetic } \\
\text { Nanoparticles }\end{array}$ & $\begin{array}{c}\text { Polyethylene Glycol, } \\
\text { Antibody (anti- } \\
\text { EGFR) }\end{array}$ & $\begin{array}{l}\text { MRI, } \\
\text { CLSM, } \\
\text { FMT }\end{array}$ & $\begin{array}{l}\text { In vivo / In vitro } \\
\text { (MDA-MB-231, } \\
\text { MDA-MB-453 } \\
\text { cells) }\end{array}$ & & [73] \\
\hline
\end{tabular}




\begin{tabular}{|c|c|c|c|c|c|}
\hline Gold Nanoparticles & $\begin{array}{l}\text { Thiol-PEG, } \\
\text { 3-Aminopropyl } \\
\text { triethoxysilane }\end{array}$ & $\begin{array}{l}\text { Fluorescence } \\
\text { imaging }\end{array}$ & $\begin{array}{l}\text { In vivo / In vitro } \\
\text { (MDA-MB- } \\
\text { 231LM2 cells) }\end{array}$ & & [103] \\
\hline $\begin{array}{c}\text { Superparamagnetic } \\
\text { Iron Oxide } \\
\text { Nanocomposites }\end{array}$ & $\begin{array}{c}\text { Polyethylenimine, } \\
\text { siRNA }\end{array}$ & $\begin{array}{l}\text { MRI, } \\
\text { CLSM }\end{array}$ & $\begin{array}{c}\text { In vivo / In vitro / } \\
\text { Ex vivo } \\
\text { (MCF-7/ADR } \\
\text { cells) }\end{array}$ & & [74] \\
\hline Quantum Dots & - & $\begin{array}{l}\text { NIR, } \\
\text { CLSM }\end{array}$ & $\begin{array}{l}\text { In vitro } \\
\text { (MCF-7/WT } \\
\text { cells) }\end{array}$ & & [132] \\
\hline $\begin{array}{l}\text { Superparamagnetic } \\
\text { Iron Oxide } \\
\text { Nanoparticles }\end{array}$ & $\begin{array}{l}\text { Amino Terminal } \\
\text { Fragment, } \\
\text { Antibody } \\
\text { (SvFcEGFR) }\end{array}$ & $\begin{array}{l}\text { NIR, } \\
\text { MRI, } \\
\text { UTE }\end{array}$ & $\begin{array}{l}\text { In vivo / In vitro } \\
\text { (MiaPaCa-2, } \\
\text { 4T1CFhR cells) }\end{array}$ & & [166] \\
\hline $\begin{array}{c}\text { Superparamagnetic } \\
\text { Iron Oxide } \\
\text { Nanoparticles }\end{array}$ & $\begin{array}{c}\text { Antibody } \\
\text { (anti-ICAM1), } \\
\text { Casein }\end{array}$ & $\begin{array}{c}\text { MRI, } \\
\text { Fluorescence } \\
\text { imaging }\end{array}$ & $\begin{array}{l}\text { In vivo / In vitro } \\
\text { (MDA-MB-231, } \\
\text { MCF7, MCF10A } \\
\text { cells) }\end{array}$ & & [104] \\
\hline $\begin{array}{l}\text { Mesoporous Silica } \\
\text { Nanoparticles }\end{array}$ & $\begin{array}{l}\text { Polyethyleneimine, } \\
\text { Folic Acid, } \\
\text { RNA interference } \\
\text { (Notch-1 shRNA) }\end{array}$ & $\begin{array}{l}\text { MRI, } \\
\text { CLSM }\end{array}$ & $\begin{array}{c}\text { In vitro } \\
\text { (MDA-MB-231 } \\
\text { cells) }\end{array}$ & & [75] \\
\hline Gold Nanoparticles & Bisphosphonate & $\begin{array}{l}\text { CT, } \\
\text { X-ray }\end{array}$ & $\begin{array}{c}\text { In vitro / Ex vivo } \\
\text { (Tumor Tissue) }\end{array}$ & & [150] \\
\hline $\begin{array}{l}\text { Hyaluronic Acid } \\
\text { Derived } \\
\text { Nanoparticles }\end{array}$ & 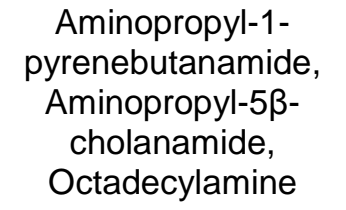 & $\begin{array}{l}\text { Fluorescence } \\
\text { imaging }\end{array}$ & $\begin{array}{l}\text { In vivo / In vitro } \\
\text { (MDA-MB-231 } \\
\text { cells) }\end{array}$ & & [105] \\
\hline $\begin{array}{l}\text { Zinc Oxide } \\
\text { Nanoparticles }\end{array}$ & $\begin{array}{c}\text { Antibody } \\
\left({ }^{64} \mathrm{Cu}, \mathrm{TRC} 105\right)\end{array}$ & $\begin{array}{c}\text { Fluorescence } \\
\text { imaging, } \\
\text { PET }\end{array}$ & $\begin{array}{l}\text { In vivo / Ex vivo } \\
\text { (4T1 cells) }\end{array}$ & & [106] \\
\hline $\begin{array}{c}\text { Superparamagnetic } \\
\text { Iron Oxide } \\
\text { Nanoparticles }\end{array}$ & $\begin{array}{l}\text { Dextran, } \\
\text { Bombesin }\end{array}$ & MRI & $\begin{array}{l}\text { In vivo / In vitro } \\
\text { (T47D) }\end{array}$ & & [169] \\
\hline Quantum Dots & $\begin{array}{l}\text { Recombinant Protein } \\
\text { (GST-EGFP-GB1), } \\
\text { Antibody }\end{array}$ & $\begin{array}{c}\text { Fluorescence } \\
\text { imaging, } \\
\text { NIR }\end{array}$ & $\begin{array}{l}\text { In vivo / In vitro } \\
\text { (T47D) }\end{array}$ & & [107] \\
\hline
\end{tabular}




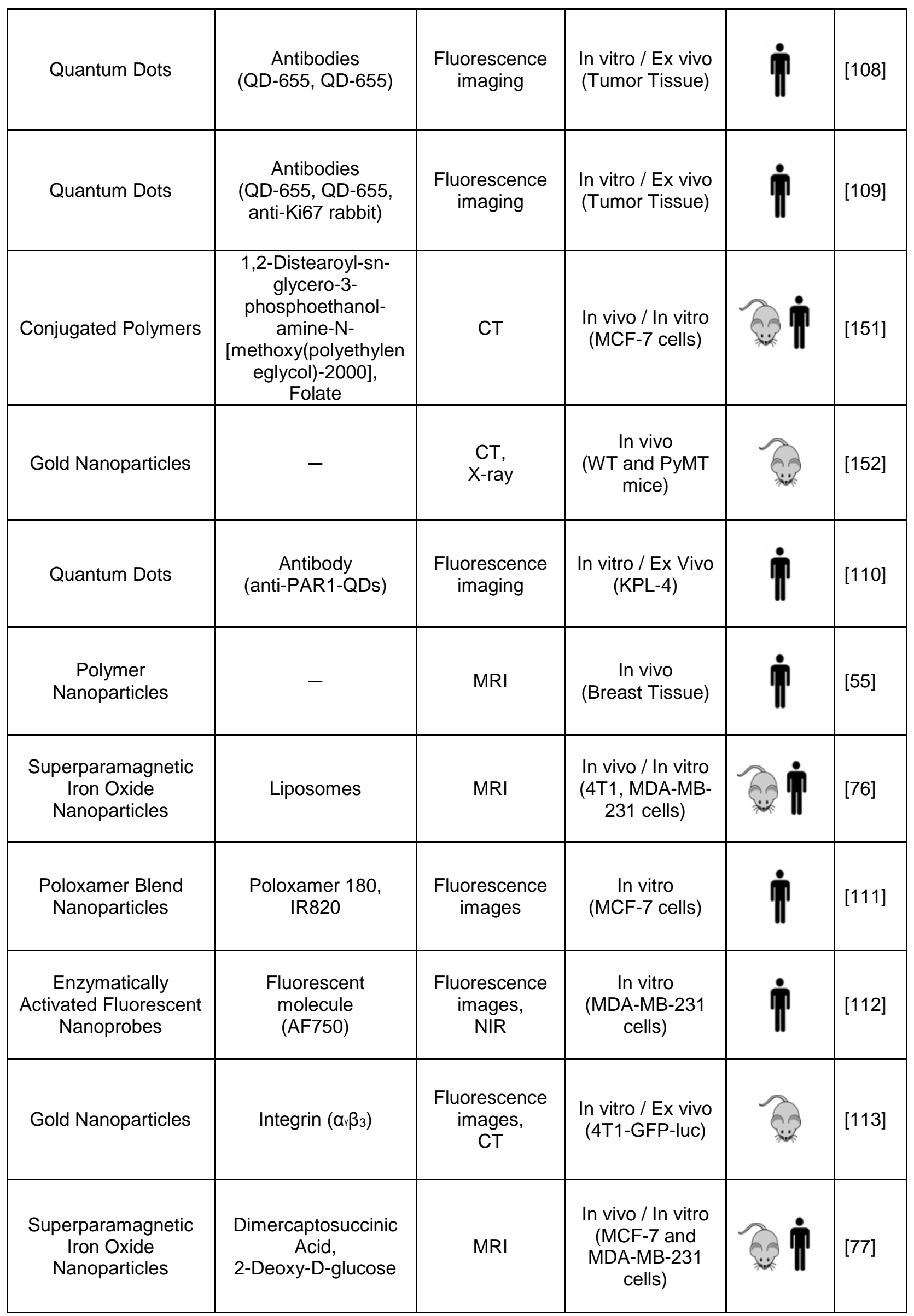




\begin{tabular}{|c|c|c|c|c|c|}
\hline $\begin{array}{l}\text { Layered Double } \\
\text { Hydroxide }\end{array}$ & Isotopes & PET & $\begin{array}{c}\text { In vivo } \\
\text { (4T1 cells) }\end{array}$ & & [162] \\
\hline Nanodiamonds & $\begin{array}{l}\text { Polyethylene glycol, } \\
\text { Antibody (anti-HER2) }\end{array}$ & PAl & $\begin{array}{l}\text { In vivo / In vitro } \\
\text { (4T1 cells) }\end{array}$ & & [179] \\
\hline Quantum Dots & $\begin{array}{c}\text { Amphiphilic } \\
\text { poly(maleic } \\
\text { anhydride-alt-1- } \\
\text { octadecene) Polymer }\end{array}$ & $\begin{array}{l}\text { Fluorescence } \\
\text { images }\end{array}$ & $\begin{array}{c}\text { In vitro } \\
\text { (SKBR3 cells) }\end{array}$ & & [114] \\
\hline Nanoparticles & $\begin{array}{l}\text { Receptor-targeted } \\
\text { surface-enhanced } \\
\text { Raman scattering }\end{array}$ & SERS & $\begin{array}{c}\text { In vitro } \\
\text { (SKBR3 cells) }\end{array}$ & & [156] \\
\hline Graphene Oxide & $\begin{array}{c}\text { Antibody } \\
\left({ }^{64} \text { Cu-NOTA-GO- }\right. \\
\text { FSHR-mAb) }\end{array}$ & $\begin{array}{c}\text { PET, } \\
\text { Fluorescence } \\
\text { images }\end{array}$ & $\begin{array}{l}\text { In vitro / In vivo } \\
\text { (MDA-MB-231 } \\
\text { cells) }\end{array}$ & & [236] \\
\hline Quantum Dots & $\begin{array}{c}\text { Antibody } \\
\left({ }^{64} \text { Cu-NOTA-GO- }\right. \\
\text { FSHR-mAb) }\end{array}$ & $\begin{array}{c}\text { MRI, } \\
\text { Fluorescence } \\
\text { images }\end{array}$ & $\begin{array}{l}\text { In vitro / In vivo } \\
\text { (MDA-MB-231 } \\
\text { cells) }\end{array}$ & & [116] \\
\hline $\begin{array}{l}\text { Gold Nanorods, } \\
\text { Superparamagnetic } \\
\text { Iron Oxide } \\
\text { Nanoparticles }\end{array}$ & $\begin{array}{l}\text { Polyethylene Glycol, } \\
\text { Cystamine } \\
\text { (anti-EGFR) }\end{array}$ & $\begin{array}{c}\text { MRI, } \\
\text { Fluorescence } \\
\text { images }\end{array}$ & $\begin{array}{l}\text { In vitro } \\
\text { (MCF7-231 } \\
\text { cells) }\end{array}$ & & [78] \\
\hline SERS Nanoparticles & $\begin{array}{c}\text { Antibodies } \\
\text { (mAb anti-EGFR, } \\
\text { anti-HER2, anti- } \\
\text { CD44 / CD24) }\end{array}$ & SERS & $\begin{array}{l}\text { In vivo / Ex vivo } \\
\text { (A431 cells) }\end{array}$ & & [157] \\
\hline Silicon Nanoparticles & - & SERS & $\begin{array}{c}\text { In vitro } \\
\text { (MCF-7 cells) }\end{array}$ & & [158] \\
\hline $\begin{array}{l}\text { Luminomagnetic } \\
\text { Nanorods }\end{array}$ & - & $\begin{array}{l}\text { Fluorescence } \\
\text { images }\end{array}$ & $\begin{array}{c}\text { In vitro } \\
\text { (T47D, MDA- } \\
\text { MB-231 cells) }\end{array}$ & & [117] \\
\hline $\begin{array}{l}\text { Superparamagnetic } \\
\text { Iron Oxide } \\
\text { Nanoparticles }\end{array}$ & $\begin{array}{l}\text { D/L-Lactide/Glycolide } \\
\text { Copolymer }\end{array}$ & $\begin{array}{l}\text { Fluorescence } \\
\text { images }\end{array}$ & $\begin{array}{l}\text { In vitro / In vivo } \\
\text { (CT26, 4T1, } \\
\text { LLC, B16F10 } \\
\text { cells) }\end{array}$ & & [118] \\
\hline
\end{tabular}




\begin{tabular}{|c|c|c|c|c|}
\hline Quantum Dots & $\begin{array}{l}\text { Metal-free/cadmium- } \\
\text { free (bio CFQD®) }\end{array}$ & CLSM & $\begin{array}{l}\text { In vitro / Ex vivo } \\
\text { (MCF-7 cells) }\end{array}$ & [133] \\
\hline $\begin{array}{l}\text { Polyamidoamine- } \\
\text { based Silica } \\
\text { Nanoparticles }\end{array}$ & $\begin{array}{c}\text { Antibody } \\
\text { (anti-HER2) }\end{array}$ & NIR & $\begin{array}{l}\text { In vitro / In vivo } \\
\text { (SK-BR3, MDA- } \\
\text { MB-231 cells) }\end{array}$ & [143] \\
\hline $\begin{array}{c}\text { Magnetic } \\
\text { Nanoparticles }\end{array}$ & - & CLSM & $\begin{array}{c}\text { In vitro } \\
\text { (MDA-MB-231 } \\
\text { cells) }\end{array}$ & [134] \\
\hline Magnetic Nanowires & Antibody & $\mathrm{FI}$ & $\begin{array}{l}\text { In vitro / Ex vivo } \\
\text { (MCF-7, MDA- } \\
\text { MB-231 cells) }\end{array}$ & [119] \\
\hline Gold Nanostars & Antibody & SERS & $\begin{array}{c}\text { In vitro / In vivo } \\
\text { (MDA-MB-231, } \\
\text { MDA231-LM2 } \\
\text { cells) }\end{array}$ & [175] \\
\hline $\begin{array}{c}\text { Zinc Oxide } \\
\text { Nanoparticles }\end{array}$ & $\begin{array}{c}\text { Carbon } \\
\text { Nanoparticles }\end{array}$ & CLSM & $\begin{array}{c}\text { In vitro } \\
\text { (MCF-7 cells) }\end{array}$ & [174] \\
\hline Liposomes & $\begin{array}{l}\text { Ammonium } \\
\text { bicarbonate }\end{array}$ & PAl & $\begin{array}{l}\text { In vitro / In vivo } \\
\text { (MDA-MB-231 } \\
\text { cells) }\end{array}$ & [177] \\
\hline $\begin{array}{l}\text { Poly(lactic-co- } \\
\text { glycolic) Acid } \\
\text { Nanoparticles }\end{array}$ & MMP2 & $\begin{array}{l}\text { MRI, } \\
\text { NIR }\end{array}$ & $\begin{array}{l}\text { In vitro / In vivo } \\
\text { (MDA-MB-231 } \\
\text { cells) }\end{array}$ & [176] \\
\hline SERS Nanoparticles & - & SERS & $\begin{array}{c}\text { In vitro } \\
\text { (SKBR3, MDA- } \\
\text { MB-231 cells) }\end{array}$ & [159] \\
\hline Quantum Dots & - & $\mathrm{FI}$ & $\begin{array}{c}\text { Ex vivo } \\
\text { (Tumor tisue) }\end{array}$ & [172] \\
\hline Gold Nanoparticles & $\begin{array}{l}\text { HEPES, } \\
\text { Bombesin, } \\
\text { PEG }\end{array}$ & X-ray & $\begin{array}{l}\text { In vitro / In vivo } \\
\text { (T47D cells) }\end{array}$ & [161] \\
\hline $\begin{array}{l}\text { Superparamagnetic } \\
\text { Iron Oxide } \\
\text { Nanoparticles }\end{array}$ & $\begin{array}{l}\text { Fluorescein-5- } \\
\text { maleimide-labeled } \\
\text { DARPin G3 }\end{array}$ & MRI & $\begin{array}{c}\text { In vitro / In vivo } \\
\text { (SKBR-3, MDA- } \\
\text { MB-231, HL- } \\
7702 \text { cells) }\end{array}$ & [170] \\
\hline
\end{tabular}

* The reference numbers in the table refer to those in the main text. 
Table S3: Theranostic applications

\begin{tabular}{|c|c|c|c|c|c|}
\hline Material & $\begin{array}{l}\text { Conjugated } \\
\text { molecules }\end{array}$ & $\begin{array}{l}\text { Theranostic } \\
\text { applications }\end{array}$ & Model & Cell type & Ref.* \\
\hline $\begin{array}{c}\text { Magnetic } \\
\text { Nanoparticles }\end{array}$ & $\begin{array}{c}\text { Oleic Acid, } \\
\text { Copolymers } \\
\text { (Pluronic®F68, F108, } \\
\text { L64, Tetronic®T904, } \\
\text { T908) }\end{array}$ & $\begin{array}{l}\text { Tumor } \\
\text { Detection }\end{array}$ & $\begin{array}{l}\text { In vivo / In vitro } \\
\text { (MCF-7 cells) }\end{array}$ & & [182] \\
\hline $\begin{array}{l}\text { Superparamagnetic } \\
\text { Iron Oxide } \\
\text { Nanoparticles }\end{array}$ & $\begin{array}{l}\text { Dextran (T-40), } \\
\text { Antibody (Herceptin) }\end{array}$ & $\begin{array}{c}\text { Tumor } \\
\text { Detection, } \\
\text { Drug Delivery }\end{array}$ & $\begin{array}{c}\text { In vivo / In vitro } \\
\text { (MCF-7, BT- } \\
\text { 474, SKBR-3, } \\
\text { MDA-MB-231 } \\
\text { cells) }\end{array}$ & & [33] \\
\hline Gold Nanorods & $\begin{array}{l}\text { Iron Nanoaprticles, } \\
\text { Poly ethylene Glycol, } \\
\text { Antibody (Herceptin) }\end{array}$ & $\begin{array}{c}\text { Tumor } \\
\text { Detection, } \\
\text { Drug Delivery }\end{array}$ & $\begin{array}{c}\text { In vitro } \\
\text { (MCF-7, SK-BR- } \\
3 \text { cells }\end{array}$ & & [32] \\
\hline Gold Nanorods & $\begin{array}{l}\text { Antibody (Herceptin), } \\
\text { Polyethylene Glycol }\end{array}$ & $\begin{array}{l}\text { Tumor } \\
\text { Detection, } \\
\text { Delivery }\end{array}$ & $\begin{array}{l}\text { In vivo / In vitro / } \\
\text { Ex vivo } \\
\text { (MCF-7, BT-474 } \\
\text { and SKBR-3 } \\
\text { cells) } \\
\end{array}$ & & [31] \\
\hline $\begin{array}{c}\text { Calcium } \\
\text { Phosphosilicate } \\
\text { Composite } \\
\text { Nanoparticles }\end{array}$ & $\begin{array}{l}\text { Antibody } \\
\text { (anti-CD71), } \\
\text { Avidin }\end{array}$ & $\begin{array}{c}\text { Tumor } \\
\text { Detection, } \\
\text { Drug Delivery }\end{array}$ & $\begin{array}{l}\text { In vivo / In vitro } \\
\text { (BxPC-3, MDA- } \\
\text { MB-231 cells) }\end{array}$ & & [214] \\
\hline $\begin{array}{c}\text { Single-Walled } \\
\text { Carbon Nanotubes }\end{array}$ & $\begin{array}{c}\text { Copolymers } \\
\text { (Pluronic® F127) }\end{array}$ & $\begin{array}{l}\text { Thermal } \\
\text { Therapy }\end{array}$ & $\begin{array}{c}\text { In vitro } \\
\text { (Tumor Tissue) }\end{array}$ & & [210] \\
\hline $\begin{array}{c}\text { Magnetic } \\
\text { Nanoparticles }\end{array}$ & $\begin{array}{c}\text { Oleic Acid, } \\
\text { NIR dye }(5700,5177, \\
2826,6825,5491), \\
\text { Copolymers } \\
\left.\text { (Pluronic }{ }^{8} \mathrm{~F} 127\right)\end{array}$ & $\begin{array}{l}\text { Tumor } \\
\text { Detection }\end{array}$ & $\begin{array}{l}\text { In vivo / Ex vivo } \\
\text { (MCF-7 cells) }\end{array}$ & & [183] \\
\hline $\begin{array}{c}\text { Magnetic } \\
\text { Nanoparticles }\end{array}$ & $\begin{array}{c}\text { Dextran (T-40), } \\
\text { NIR Dye (Cy5.5), } \\
\text { Peptides (EPPT), } \\
\text { siRNA }\end{array}$ & $\begin{array}{l}\text { Drug Delivery, } \\
\text { Cancer } \\
\text { Therapy }\end{array}$ & $\begin{array}{l}\text { In vivo / In vitro / } \\
\text { Ex vivo } \\
\text { (BT-20, CAPAN- } \\
\text { 2, LS-174T } \\
\text { cells) }\end{array}$ & & [43] \\
\hline $\begin{array}{l}\text { Silica-Gold } \\
\text { Nanoshells }\end{array}$ & $\begin{array}{l}\text { Polyethylene Glycol, } \\
\text { Antibody (anti-HER2) }\end{array}$ & $\begin{array}{l}\text { Photothermal } \\
\text { Therapy, } \\
\text { Gene Therapy }\end{array}$ & $\begin{array}{l}\text { In vivo / In vitro } \\
\text { (SKBR3, } \\
\text { MDAMB231, } \\
\text { BT474AZ cells) }\end{array}$ & & [180] \\
\hline $\begin{array}{l}\text { Silica-Gold } \\
\text { Nanoshells }\end{array}$ & $\begin{array}{c}\text { Polyethylene glycol, } \\
\text { 3,3'-diethylthia- } \\
\text { tricarbocyanine } \\
\text { iodide }\end{array}$ & $\begin{array}{l}\text { Photodynamic } \\
\text { Therapy }\end{array}$ & $\begin{array}{c}\text { In vitro } \\
\text { (BT549 cells) }\end{array}$ & & [190] \\
\hline
\end{tabular}




\begin{tabular}{|c|c|c|c|c|c|}
\hline $\begin{array}{c}\text { Magnetic } \\
\text { Nanoparticles }\end{array}$ & $\begin{array}{l}\text { Human Serum } \\
\text { Albumin, } \\
\text { Doxorubicin }\end{array}$ & $\begin{array}{c}\text { Tumor } \\
\text { Detection, } \\
\text { Drug Delivery }\end{array}$ & $\begin{array}{c}\text { In vivo / In vitro / } \\
\text { Ex vivo } \\
\text { (4T1 cells })\end{array}$ & & [184] \\
\hline $\begin{array}{c}\text { Thiol-functionalized } \\
\text { Hyaluronic Acid }\end{array}$ & $\begin{array}{c}\text { Allyloxy } \\
\text { 12Cucurbit[6]uril, } \\
\text { Fluorescein } \\
\text { Isothiocyanate }\end{array}$ & $\begin{array}{l}\text { Drug Delivery, } \\
\text { Tissue } \\
\text { Engineering }\end{array}$ & $\begin{array}{c}\text { In vitro } \\
\text { (B16F1, } \\
\text { FPRL1/MCF-7 } \\
\text { cells) }\end{array}$ & & [223] \\
\hline $\begin{array}{c}\text { Magnetic } \\
\text { Nanoparticles }\end{array}$ & $\begin{array}{l}\beta \text {-Cyclodextrin, } \\
\text { Copolymer } \\
\text { (Pluronic®F127), } \\
\text { Curcumin }\end{array}$ & $\begin{array}{l}\text { Drug Delivery, } \\
\text { Cancer } \\
\text { Therapy }\end{array}$ & $\begin{array}{c}\text { In vitro } \\
\text { (MDA-MB-231, } \\
\text { MCF-7, } \\
\text { A2780CP, PC3 } \\
\text { cells) }\end{array}$ & & [41] \\
\hline $\begin{array}{c}\text { Magnetic } \\
\text { Nanoparticles }\end{array}$ & $\begin{array}{l}\text { Antibody } \\
\text { (anti-HER2) }\end{array}$ & $\begin{array}{l}\text { Cancer } \\
\text { Therapy }\end{array}$ & $\begin{array}{l}\text { In vivo / Ex vivo } \\
\text { (MCF-7 cells) }\end{array}$ & & [186] \\
\hline Gold Nanoparticles & $\begin{array}{c}\text { Molecule } \\
\text { (DOTA-64 } \mathrm{Cu} \text {, } \\
\text { Amine Polyethylene } \\
\text { Glycol Thiol }\end{array}$ & $\begin{array}{l}\text { Tumor } \\
\text { Detection }\end{array}$ & $\begin{array}{c}\text { In vivo } \\
\text { (EMT-6 cells) }\end{array}$ & & [195] \\
\hline Liposomes & $\begin{array}{c}\text { Docetaxel, } \\
\text { D- } \alpha \text {-Tocopheryl } \\
\text { Acid Succinate, } \\
\text { Quantum Dots }\end{array}$ & $\begin{array}{c}\text { Tumor } \\
\text { Detection, } \\
\text { Drug Delivery }\end{array}$ & $\begin{array}{c}\text { In vitro } \\
\text { (MCF-7 cells) }\end{array}$ & & [44] \\
\hline $\begin{array}{c}\text { Magnetic } \\
\text { Nanoparticles }\end{array}$ & $\begin{array}{l}\text { Copolymers } \\
\text { (Pluronic®F68), } \\
\text { Curcumin }\end{array}$ & Drug Delivery & $\begin{array}{c}\text { In vitro } \\
\text { (MDA-MB-231 } \\
\text { cells) }\end{array}$ & & [40] \\
\hline Gold Nanoparticles & Polyethylene glycol & $\begin{array}{l}\text { Phototermal } \\
\text { Therapy, } \\
\text { Tumor } \\
\text { Detection }\end{array}$ & $\begin{array}{l}\text { In vivo / In vitro } \\
\text { (MDA-MB-435 } \\
\text { cells) }\end{array}$ & & [196] \\
\hline $\begin{array}{c}\text { Calcium } \\
\text { Phosphosilicate } \\
\text { Nanoparticles }\end{array}$ & $\begin{array}{l}\text { Polyethylene glycol, } \\
\text { Indocyanine green }\end{array}$ & $\begin{array}{c}\text { Photodynamic } \\
\text { Therapy }\end{array}$ & $\begin{array}{c}\text { In vivo } \\
\text { (410.4, MDA- } \\
\text { MB-231, Panc- } \\
\text { 02, BxPC-3- } \\
\text { GFP, SAOS-2- } \\
\text { LM7 cells) }\end{array}$ & & [215] \\
\hline $\begin{array}{c}\text { Reduced } \\
\text { Graphene Oxide }\end{array}$ & $\begin{array}{c}\text { Antibody } \\
\text { (Anti-CD105), } \\
{ }^{64} \text { Cu-NOTA-TRC105 }\end{array}$ & $\begin{array}{l}\text { Phototermal } \\
\text { Therapy }\end{array}$ & $\begin{array}{l}\text { In vivo / in vitro / } \\
\text { Ex vivo } \\
(4 \mathrm{~T} 1, \mathrm{MCF}-7 \\
\text { cells) }\end{array}$ & & [236] \\
\hline $\begin{array}{l}\text { Heparine/Folic acid } \\
\text { Nanoparticles }\end{array}$ & IR-780 iodide & $\begin{array}{l}\text { Phototermal } \\
\text { Therapy }\end{array}$ & $\begin{array}{l}\text { In vivo / In vitro } \\
\text { (MCF-7) }\end{array}$ & & [224] \\
\hline
\end{tabular}




\begin{tabular}{|c|c|c|c|c|c|}
\hline $\begin{array}{l}\text { PMAA-PS 80-g-St- } \\
\text { DTPA polymer }\end{array}$ & $\begin{array}{l}\text { Gadolinium, } \\
\text { Doxorubicin }\end{array}$ & Drug Delivery & $\begin{array}{l}\text { In vivo / In vitro } \\
\text { (EMT6/WT } \\
\text { cells) }\end{array}$ & & [226] \\
\hline $\begin{array}{c}\text { Multiwalled } \\
\text { Carbon Nanotubes }\end{array}$ & $\begin{array}{c}\text { Alexa-fluor } \\
\text { (AF488/647), } \\
\text { Radionucleide } \\
\text { (Technitium-99m), } \\
\text { Folic Acid, } \\
\text { Methotrexate }\end{array}$ & $\begin{array}{c}\text { Tumor } \\
\text { Detection, } \\
\text { Drug Delivery }\end{array}$ & $\begin{array}{l}\text { In vivo / In vitro } \\
\text { (MCF-7, A549 } \\
\text { cells) }\end{array}$ & & [48] \\
\hline $\begin{array}{l}\text { Silica-Gold } \\
\text { Nanoshells }\end{array}$ & $\begin{array}{c}\text { Protoporphyrin IX, } \\
\text { Peptide (TAT), } \\
\text { 3,3'-diethylthia- } \\
\text { dicarbocyanine } \\
\text { iodide }\end{array}$ & $\begin{array}{c}\text { Photodynamic } \\
\text { Therapy }\end{array}$ & $\begin{array}{c}\text { In vitro } \\
\text { (BT-549 cells) }\end{array}$ & & [191] \\
\hline $\begin{array}{c}\text { Magnetic } \\
\text { Nanoparticles }\end{array}$ & $\begin{array}{l}\text { Polyethylene glycol, } \\
\text { Folic Acid, } \\
\text { Tamoxifen }\end{array}$ & $\begin{array}{c}\text { Tumor } \\
\text { Detection, } \\
\text { Drug Delivery }\end{array}$ & $\begin{array}{c}\text { In vitro } \\
\text { (MCF-7 cells) }\end{array}$ & & [47] \\
\hline $\begin{array}{c}\text { Magnetic } \\
\text { Nanoparticles }\end{array}$ & $\begin{array}{c}\text { Acid } \\
\text { (PHBA)-b-P(OEGA), } \\
\text { Doxorubicin }\end{array}$ & Drug delivery & $\begin{array}{c}\text { In vitro } \\
\text { (MCF-7, H1299 } \\
\text { cells) }\end{array}$ & & [188] \\
\hline Gold Nanorods & $\begin{array}{l}\text { Polyethylene Glycol, } \\
\text { Chlorin e6 }\end{array}$ & $\begin{array}{c}\text { Photothermal } \\
\text { Therapy }\end{array}$ & $\begin{array}{l}\text { In vivo / In vitro } \\
\text { (MDA-MB-453 } \\
\text { cells) }\end{array}$ & & [206] \\
\hline $\begin{array}{l}\text { Mesoporous Silica } \\
\text { Nanoparticles }\end{array}$ & $\begin{array}{c}\text { Polyethylene glycol, } \\
\text { Antibody (TRC105), } \\
\text { Doxorubicin }\end{array}$ & $\begin{array}{c}\text { Drug delivery, } \\
\text { Tumor } \\
\text { Detection }\end{array}$ & $\begin{array}{c}\text { In vivo / In vitro / } \\
\text { Ex vivo } \\
\text { (4T1, MCF7 } \\
\text { cells) }\end{array}$ & & [201] \\
\hline $\begin{array}{c}\text { Hydrotropic } \\
\text { Oligomer-Conjugated } \\
\text { Nanoparticles }\end{array}$ & $\begin{array}{l}\text { Glycol, Chitosan, } \\
\text { Paclitaxel (PTX) }\end{array}$ & $\begin{array}{c}\text { Cancer } \\
\text { Therapy, } \\
\text { Drug Delivery }\end{array}$ & $\begin{array}{l}\text { In vivo / In vitro / } \\
\text { Ex vivo } \\
\text { (MDAMB-231 } \\
\text { cells) }\end{array}$ & & [227] \\
\hline $\begin{array}{l}\text { Silica-Gold } \\
\text { Nanoshells }\end{array}$ & - & $\begin{array}{c}\text { Photothermal } \\
\text { Therapy, } \\
\text { Ultrasonograp } \\
\text { hy }\end{array}$ & $\begin{array}{l}\text { In vivo / In vitro } \\
\text { (BT474 cells) }\end{array}$ & & [192] \\
\hline $\begin{array}{c}\text { Magnetic } \\
\text { Nanoparticles }\end{array}$ & $\begin{array}{c}\text { NIR Dye (830-ATF), } \\
\text { Doxorubicin }\end{array}$ & $\begin{array}{c}\text { Tumor } \\
\text { Detection, } \\
\text { Drug Delivery }\end{array}$ & $\begin{array}{l}\text { In vivo / In vitro } \\
\text { (MDA-MB-231, } \\
\text { MIA PaCa-2 } \\
\text { cells) }\end{array}$ & & [185] \\
\hline Gold Nanorods & $\begin{array}{l}\text { Fluorescein } \\
\text { Isothiocyanate, } \\
\text { Fluorophore } \\
\text { (TAMRA), } \\
\text { siRNA }\end{array}$ & Gene Therapy & $\begin{array}{c}\text { In vitro } \\
\text { (MCF-7, SK-OV- } \\
3 \text { cells) }\end{array}$ & & [205] \\
\hline
\end{tabular}




\begin{tabular}{|c|c|c|c|c|c|}
\hline $\begin{array}{l}\mathrm{N}-(2-\text { Hydroxypropyl) } \\
\text { methacrylamide } \\
\text { Copolymer }\end{array}$ & $\begin{array}{c}\text { Paclitaxel, } \\
\text { NIR Dye (SQ-Cy5) }\end{array}$ & $\begin{array}{c}\text { Tumor } \\
\text { Detection, } \\
\text { Drug Delivery }\end{array}$ & $\begin{array}{l}\text { In vivo / In vitro } \\
(4 \mathrm{~T} 1 \text { cells })\end{array}$ & & [37] \\
\hline Gold Nanoparticles & $\begin{array}{l}\text { SERS Molecules } \\
\text { (MGITC, Rh6G, Cy5) }\end{array}$ & $\begin{array}{l}\text { Tumor } \\
\text { Detection }\end{array}$ & $\begin{array}{l}\text { in vivo / In vitro } \\
\text { (MDA-MB-231 } \\
\text { cells) }\end{array}$ & & [197] \\
\hline $\begin{array}{l}\text { Mesoporous Silica } \\
\text { Nanoparticles }\end{array}$ & $\begin{array}{c}\text { Fluorescein } \\
\text { Isothiocyanate, } \\
\text { Antibody } \\
\text { (Herceptin+D8) }\end{array}$ & $\begin{array}{l}\text { Drug Delivery, } \\
\text { Tumor } \\
\text { Detection }\end{array}$ & $\begin{array}{c}\text { In vitro } \\
\text { (MDA-MB-231, } \\
\text { SK-BR-3 cells) }\end{array}$ & & [30] \\
\hline Liposomes & $\begin{array}{c}\text { Magnetic } \\
\text { Nanoparticles, } \\
\text { Mitoxantrone }\end{array}$ & $\begin{array}{c}\text { Tumor } \\
\text { Detection, } \\
\text { Drug Delivery }\end{array}$ & $\begin{array}{c}\text { In vivo / In vitro } \\
\text { (MCF-7, SK-OV- } \\
3 \text { cells) }\end{array}$ & & [46] \\
\hline $\begin{array}{l}\text { Poly(methacrylic } \\
\text { acid)-polysorbate } \\
\text { 80-grafted-starch }\end{array}$ & $\begin{array}{c}\text { Gadolinium, } \\
\text { HiLyte Fluor 750, } \\
\text { FA dye, } \\
\text { Doxorubicin }\end{array}$ & $\begin{array}{c}\text { Tumor } \\
\text { Detection, } \\
\text { Drug Delivery }\end{array}$ & $\begin{array}{l}\text { In vivo / In vitro / } \\
\text { Ex vivo } \\
\text { (MDA-MB-231 } \\
\text { cells) }\end{array}$ & & [225] \\
\hline $\begin{array}{l}\text { Copper(II) Sulfide } \\
\text { Nanoparticles }\end{array}$ & Polyethylene Glycol & $\begin{array}{c}\text { Photoacoustic } \\
\text { Tomography, } \\
\text { Tumor } \\
\text { Detection }\end{array}$ & $\begin{array}{l}\text { In vivo / In vitro } \\
\text { (4T1 cells) }\end{array}$ & & [218] \\
\hline $\begin{array}{c}\text { Mesoporous Magnetic } \\
\text { Gold Nanoclusters }\end{array}$ & $\begin{array}{l}\text { Doxorubicin, } \\
\text { Pentoxifylline }\end{array}$ & $\begin{array}{l}\text { Photothermal } \\
\text { Therapy, } \\
\text { Drug delivery }\end{array}$ & $\begin{array}{l}\text { In vivo / In vitro } \\
\text { (4T1, MCF-7 } \\
\text { cells) }\end{array}$ & & [49] \\
\hline $\begin{array}{l}\text { Tungsten Oxide } \\
\text { Nanoparticles }\end{array}$ & Polyethylene Glycol & $\begin{array}{c}\text { Photothermal } \\
\text { Therapy }\end{array}$ & $\begin{array}{l}\text { In vivo / In vitro } \\
\text { (4T1 cells) }\end{array}$ & & [219] \\
\hline Quantum Dots & $\begin{array}{l}\text { Mercaptoundecanoic } \\
\text { Acid, Antibody } \\
\text { (Anti-HER2) }\end{array}$ & $\begin{array}{l}\text { Tumor } \\
\text { Detection }\end{array}$ & $\begin{array}{c}\text { In vitro } \\
\text { (SK-BR-3, MCF- } \\
7 \text { cells) }\end{array}$ & & [217] \\
\hline $\begin{array}{c}\text { Carbon } \\
\text { Nano-Onions }\end{array}$ & $\begin{array}{c}\text { Boron } \\
\text { Dipyromethene }\end{array}$ & - & $\begin{array}{c}\text { In vitro } \\
\text { (MCF7 cells) }\end{array}$ & & [238] \\
\hline $\begin{array}{c}\text { Singlewalled } \\
\text { Carbon Nanotubes }\end{array}$ & $\begin{array}{l}\text { Endoglin/CD105, } \\
\text { Doxorubicin }\end{array}$ & $\begin{array}{c}\text { Drug Delivery, } \\
\text { Tumor } \\
\text { Detection }\end{array}$ & $\begin{array}{l}\text { In vitro / In vivo } \\
\text { (4T1 cells) }\end{array}$ & & [211] \\
\hline
\end{tabular}




\begin{tabular}{|c|c|c|c|c|}
\hline $\begin{array}{l}\text { Theranostic } \\
\text { Nanoparticles }\end{array}$ & $\begin{array}{c}\text { Chlorin e6, } \\
\text { Monomethoxy } \\
\text { polyethylene glycol }\end{array}$ & $\begin{array}{c}\text { Chemotherapy } \\
\text { Tumor } \\
\text { Detection }\end{array}$ & $\begin{array}{c}\text { In vitro } \\
\text { (MDA-MB-231 } \\
\text { TNBC cells) }\end{array}$ & [230] \\
\hline Gold Nanoparticles & 5-Fluorouracil & $\begin{array}{l}\text { Tumor } \\
\text { Detection, } \\
\text { Cancer } \\
\text { Therapy }\end{array}$ & $\begin{array}{l}\text { In vitro / In vivo } \\
\text { (MDA-MB-231 } \\
\text { cells) }\end{array}$ & [198] \\
\hline Star polymers & $\begin{array}{l}\text { Doxorubicin, } \\
\text { Gadolinium }\end{array}$ & Drug Delivery & $\begin{array}{c}\text { In vitro } \\
\text { (MCF7 cells) }\end{array}$ & [231] \\
\hline Gold Nanorods & $\begin{array}{l}\text { Tetraethylortho } \\
\text { silicate, } \\
\text { G70Cetyltrimethylam } \\
\text { monium bromide }\end{array}$ & $\begin{array}{l}\text { Photothermal } \\
\text { Therapy }\end{array}$ & $\begin{array}{c}\text { In vitro } \\
\text { (MDA-MB-231 } \\
\text { cells) }\end{array}$ & [207] \\
\hline $\begin{array}{c}\text { Magnetic } \\
\text { Nanoparticles }\end{array}$ & $\begin{array}{c}\text { Tetraethylortho- } \\
\text { silicate, } \\
\text { N-(2-aminoethyl)-3- } \\
\text { aminopropyltrimetho- } \\
\text { xysilane, } \\
\text { Polyethylenimine, } \\
\text { Small hairpin RNA }\end{array}$ & Gene Delivery & $\begin{array}{c}\text { In vitro } \\
\text { (MCF7 cells) }\end{array}$ & [189] \\
\hline $\begin{array}{c}\text { Polymeric } \\
\text { Theranostic } \\
\text { Nanoparticles }\end{array}$ & Docetaxel & $\begin{array}{l}\text { Chemotherapy } \\
\text { Drug Delivery }\end{array}$ & $\begin{array}{l}\text { In vivo / In vitro } \\
\text { (MDA-MB-231 } \\
\text { cells) }\end{array}$ & [226] \\
\hline $\begin{array}{c}\text { Singlewalled } \\
\text { Carbon Nanotubes }\end{array}$ & $\begin{array}{l}\text { Doxorubicin, } \\
\text { Hyaluronic acid, } \\
\text { Gadolinium }\end{array}$ & $\begin{array}{l}\text { Photothermal } \\
\text { Therapy, } \\
\text { Tumor } \\
\text { targeting }\end{array}$ & $\begin{array}{l}\text { In vitro / In vivo } \\
\text { (MCF-7) }\end{array}$ & [212] \\
\hline Quantum Dots & $\begin{array}{l}\text { Chitosan, } \\
\text { Folic acid }\end{array}$ & $\begin{array}{c}\text { Tumor } \\
\text { imaging, } \\
\text { Drug Delivery }\end{array}$ & $\begin{array}{c}\text { In vitro } \\
\text { (MDA-MB-231, } \\
\text { MCF-7 cells) }\end{array}$ & [241] \\
\hline Liposomes & Doxorubicin & $\begin{array}{c}\text { Tumor } \\
\text { imaging, } \\
\text { Drug Delivery }\end{array}$ & $\begin{array}{c}\text { In vivo / In vitro / } \\
\text { Ex vivo } \\
\text { (MDA-MB-468, } \\
\text { SKBR3 cells) }\end{array}$ & [208] \\
\hline Gold Nanoparticles & Doxorubicin & $\begin{array}{l}\text { Drug Delivery, } \\
\text { Cancer } \\
\text { Therapy }\end{array}$ & $\begin{array}{c}\text { In vitro } \\
\text { (MCF7 cells) }\end{array}$ & [199] \\
\hline Gold Nanoparticles & $\begin{array}{c}\text { Antibody(anti-HER2), } \\
\text { Gadolinium }\end{array}$ & $\begin{array}{l}\text { Tumor } \\
\text { Detection, } \\
\text { Cancer } \\
\text { Therapy }\end{array}$ & $\begin{array}{c}\text { In vitro } \\
\text { (A549, SKBR-3 } \\
\text { cells) }\end{array}$ & [29] \\
\hline
\end{tabular}




\begin{tabular}{|c|c|c|c|c|c|}
\hline Nanocarriers & Paclitaxel & $\begin{array}{c}\text { Drug Delivery, } \\
\text { Cancer } \\
\text { Therapy }\end{array}$ & $\begin{array}{c}\text { In vitro } \\
\text { (MCF-7/ADR } \\
\text { cells) }\end{array}$ & & [34] \\
\hline Nanoreporters & Doxorubicin & $\begin{array}{c}\text { Drug Delivery, } \\
\text { Cancer } \\
\text { Therapy }\end{array}$ & In vivo / Ex vivo & & [233] \\
\hline Gold Nanoroads & $\begin{array}{l}\text { Cisplatin, } \\
\text { Folic acid }\end{array}$ & $\begin{array}{l}\text { Tumor } \\
\text { Detection, } \\
\text { Cancer } \\
\text { Therapy } \\
\end{array}$ & $\begin{array}{c}\text { In vitro / In vivo / } \\
\text { Ex vivo } \\
\text { (4T1 cells) }\end{array}$ & & [203] \\
\hline Gold Nanoparticles & $\begin{array}{l}\text { Doxorubicin, } \\
\text { Gadolinium }\end{array}$ & $\begin{array}{l}\text { Drug Delivery, } \\
\text { Photothermal } \\
\text { Therapy }\end{array}$ & $\begin{array}{c}\text { In Vivo } \\
\text { (Tumor models) }\end{array}$ & & [18] \\
\hline $\begin{array}{l}\text { Porous Silicon } \\
\text { Nanoparticles }\end{array}$ & - & $\begin{array}{l}\text { Tumor } \\
\text { Detection, } \\
\text { Cancer } \\
\text { Therapy }\end{array}$ & $\begin{array}{c}\text { In vitro } \\
\text { (MCF7 cells) }\end{array}$ & & [202] \\
\hline Gold Nanoparticles & Doxorubicin & $\begin{array}{c}\text { Cancer } \\
\text { Detection, } \\
\text { Photothermal } \\
\text { Therapy }\end{array}$ & $\begin{array}{l}\text { In vitro / In vivo } \\
\text { (MCF7 cells) }\end{array}$ & & [200] \\
\hline $\begin{array}{c}\text { Singlewalled } \\
\text { Carbon Nanotubes }\end{array}$ & $\begin{array}{l}\text { Polyethylene Glycol, } \\
\text { NIR Dye (Cy5.5) }\end{array}$ & $\begin{array}{c}\text { Cancer } \\
\text { Detection, } \\
\text { Photothermal } \\
\text { Therapy }\end{array}$ & $\begin{array}{l}\text { In vitro / In vivo } \\
\text { (MCF7 cells) }\end{array}$ & & [213] \\
\hline Gold Nanoparticles & $\begin{array}{l}\text { Doxorubicin, } \\
\text { Folic acid, } \\
\text { BSA }\end{array}$ & $\begin{array}{l}\text { Chemo- } \\
\text { photothermal } \\
\text { Synergistic } \\
\text { Therapy }\end{array}$ & $\begin{array}{l}\text { In vitro / In vivo } \\
\text { (MCF7 cells) }\end{array}$ & & [27] \\
\hline $\begin{array}{l}\text { Superparamagnetic } \\
\text { Iron Oxide } \\
\text { Nanoparticles }\end{array}$ & Hyaluronan & $\begin{array}{c}\text { Cancer } \\
\text { Detection, } \\
\text { Photothermal } \\
\text { Therapy }\end{array}$ & $\begin{array}{l}\text { In vitro / In vivo } \\
\text { (MDA-MB-231 } \\
\text { cells) }\end{array}$ & & [181] \\
\hline $\begin{array}{l}\text { Superparamagnetic } \\
\text { Iron Oxide } \\
\text { Nanoparticles }\end{array}$ & $\begin{array}{l}\text { Folic Acid, } \\
\text { Doxorubicin }\end{array}$ & $\begin{array}{l}\text { Tumor } \\
\text { Detection, } \\
\text { Cancer } \\
\text { Therapy }\end{array}$ & $\begin{array}{l}\text { In vitro / In vivo } \\
\text { (MCF7 cells) }\end{array}$ & & [26] \\
\hline $\begin{array}{l}\text { Theranostic polymeric } \\
\text { Nanoparticles }\end{array}$ & Docetaxel & $\begin{array}{l}\text { Tumor } \\
\text { Detection, } \\
\text { Cancer } \\
\text { Therapy }\end{array}$ & $\begin{array}{c}\text { In vitro } \\
\text { (MCF7, SKOV-3 } \\
\text { cells) }\end{array}$ & & [51] \\
\hline Liposomes & $\begin{array}{l}\text { Doxorubicin, } \\
\text { Cisplatin, } \\
\text { Gemcitabine }\end{array}$ & $\begin{array}{c}\text { Tumor } \\
\text { Detection, } \\
\text { Cancer } \\
\text { Therapy }\end{array}$ & $\begin{array}{l}\text { In vitro / In vivo } \\
\text { (MDA-MB-231, } \\
4 T 1 \text { cells) }\end{array}$ & & [52] \\
\hline $\begin{array}{l}\text { Mesoporous Silica } \\
\text { Nanoparticles }\end{array}$ & Doxorubicin & $\begin{array}{c}\text { Tumor } \\
\text { Detection, } \\
\text { Cancer } \\
\text { Therapy }\end{array}$ & $\begin{array}{l}\text { In vitro / In vivo } \\
\text { (4T1 cells) }\end{array}$ & & [204] \\
\hline
\end{tabular}




\begin{tabular}{|c|c|c|c|c|c|}
\hline $\begin{array}{l}\text { Gd2O3@albumin } \\
\text { Conjugating } \\
\text { Photosensitizer }\end{array}$ & Chlorin e6 & $\begin{array}{c}\text { Cancer } \\
\text { Detection, } \\
\text { Photodynami } \\
\text { Theraphy }\end{array}$ & $\begin{array}{l}\text { In vivo / Ex vivo } \\
\text { (4T1 cells) }\end{array}$ & & [222] \\
\hline $\begin{array}{l}\text { Tumor-targeting } \\
\text { Ultrasound-triggered } \\
\text { Phase-transition } \\
\text { Nanodroplets }\end{array}$ & Nucleic Acids & $\begin{array}{l}\text { Tumor } \\
\text { Detection, } \\
\text { Cancer } \\
\text { Therapy }\end{array}$ & $\begin{array}{c}\text { In vitro / In vivo } \\
\text { (SK-BR-3, HGC- } \\
27 \text { cells) }\end{array}$ & & [234] \\
\hline $\begin{array}{l}\text { Polylactic and } \\
\text { Glycolic Acid } \\
\text { Nanoparticles }\end{array}$ & $\begin{array}{l}\text { L-Ferritin, } \\
\text { Paclitaxel }\end{array}$ & $\begin{array}{c}\text { Cancer } \\
\text { Detection, } \\
\text { Drug Delivery }\end{array}$ & $\begin{array}{c}\text { In vitro } \\
\text { (MCF7, MDA- } \\
\text { MB-231 cells) }\end{array}$ & & [228] \\
\hline $\begin{array}{l}\text { Gold Nanorods, } \\
\text { Gold Nanospheres }\end{array}$ & $\begin{array}{l}\text { Thiolated- } \\
\text { hyaluronic acid }\end{array}$ & $\begin{array}{c}\text { Cancer } \\
\text { Detection, } \\
\text { Photothermal } \\
\text { Therapy }\end{array}$ & $\begin{array}{c}\text { In vitro } \\
\text { (MCF7 cells) }\end{array}$ & & [193] \\
\hline $\begin{array}{l}\text { Carbon Nanoparticles } \\
\text { Nanodroplets }\end{array}$ & $\begin{array}{l}\text { Poly(lactic-co- } \\
\text { glycolic acid) }\end{array}$ & $\begin{array}{c}\text { Cancer } \\
\text { Detection, } \\
\text { Photothermal } \\
\text { Therapy }\end{array}$ & $\begin{array}{l}\text { In vitro / In vivo } \\
\text { (MDA-MB-231 } \\
\text { cells) }\end{array}$ & & [220] \\
\hline $\begin{array}{l}\text { Prussian blue } \\
\text { (PB)/manganese } \\
\text { dioxide Hybrid } \\
\text { Nanoparticles }\end{array}$ & - & $\begin{array}{c}\text { Cancer } \\
\text { Detection, } \\
\text { Photothermal } \\
\text { Therapy }\end{array}$ & $\begin{array}{l}\text { In vitro / In vivo } \\
\text { (MCF7 cells) }\end{array}$ & & [221] \\
\hline $\begin{array}{c}\text { Magnetic } \\
\text { Nanoparticles }\end{array}$ & Doxorubicin & $\begin{array}{l}\text { Tumor } \\
\text { Detection, } \\
\text { Cancer } \\
\text { Therapy }\end{array}$ & $\begin{array}{l}\text { In vitro / In vivo } \\
\text { (MDA-MB-231 } \\
\text { cells) }\end{array}$ & & [187] \\
\hline Gold Nanospheres & Polyethylene Glycol & $\begin{array}{c}\text { Cancer } \\
\text { Detection, } \\
\text { Photothermal } \\
\text { Therapy }\end{array}$ & $\begin{array}{l}\text { In vitro / In vivo } \\
\text { (4T1 cells) }\end{array}$ & & [194] \\
\hline $\begin{array}{l}\text { Peptide Aptamer } \\
\text { Targeted Polymers }\end{array}$ & Doxorubicin & $\begin{array}{c}\text { Cancer } \\
\text { Detection, } \\
\text { Drug Delivery }\end{array}$ & $\begin{array}{l}\text { In vitro / In vivo } \\
\text { (MDA-MA-231, } \\
\text { MDA-MB-468 }\end{array}$ & & [229] \\
\hline Liposomes & Doxorubicin & $\begin{array}{c}\text { Tumor } \\
\text { Detection, } \\
\text { Cancer } \\
\text { Therapy }\end{array}$ & $\begin{array}{l}\text { In vitro / In vivo } \\
\text { (4T1 cells) }\end{array}$ & 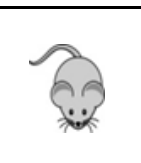 & [209] \\
\hline
\end{tabular}

\footnotetext{
* The reference numbers in the table refer to those in the main text.
} 